\title{
Does Evolutionary Psychology Show That Normativity Is Mind-Dependent?
}

\section{Citation}

Berker, Selim. 2014. "Does Evolutionary Psychology Show That Normativity Is Mind-Dependent?" In Moral Psychology and Human Agency: Philosophical Essays on the Science of Ethics, edited by Justin D'Arms and Daniel Jacobson. Oxford: Oxford University Press.

\section{Published Version}

doi:10.1093/acprof:oso/9780198717812.003.0010

\section{Permanent link}

http://nrs.harvard.edu/urn-3:HUL.InstRepos:23990502

\section{Terms of Use}

This article was downloaded from Harvard University's DASH repository, and is made available under the terms and conditions applicable to Other Posted Material, as set forth at http:// nrs.harvard.edu/urn-3:HUL.InstRepos:dash.current.terms-of-use\#LAA

\section{Share Your Story}

The Harvard community has made this article openly available.

Please share how this access benefits you. Submit a story.

\section{Accessibility}




\title{
Does Evolutionary Psychology Show That Normativity Is Mind-Dependent?
}

\author{
Selim Berker \\ Harvard University \\ sberker@fas.harvard.edu
}

[Published in Justin D'Arms and Daniel Jacobson (eds.), Moral Psychology and Human Agency: Philosophical Essays on the Science of Ethics (Oxford: Oxford University Press, 2014), 215-52. Please cite that version.]

\section{Introduction}

Suppose we grant that evolutionary forces have had a profound effect on the contours of our normative judgments and intuitions. Can we conclude anything from this about the correct metaethical theory? In particular, can we conclude anything about the ultimate grounds of normativity? I will argue that, for the most part, we cannot.

I focus here on the powerful line of argument developed by Sharon Street in an important series of articles (Street 2006; 2008b; 2009a; 2011; MSa; MSb). ${ }^{1}$ Street claims that the evolutionary origins of our normative judgments and intuitions cause insuperable epistemological difficulties for a metaethical view she calls "normative realism." I will be claiming, in reply, that there are two largely independent lines of argument in Street's work which need to be teased apart. The first of these involves a genuine appeal to evolutionary considerations, but it can fairly easily be met by her opponents. The second line of argument is more troubling; it raises a significant problem, one of the most difficult in all of philosophy, namely how to justify our reliance on our most basic cognitive faculties without relying on those same faculties in a question-begging manner. However, evolutionary considerations add little to this old problem, and rejecting normative realism is not a way to solve it.

My way of arguing for these conclusions will involve two basic strategies, deployed in tandem. First, I will be insisting that Street's own preferred metaethical view, so-called "Humean constructivism," is just as threatened by her arguments as her opponents' views are. I do so because seeing why Street is mistaken in thinking that Humean constructivism is better placed to avoid her evolutionary challenge

1 Similar evolutionary arguments have been offered by Richard Joyce (2001, ch. 6; 2006; forthcoming) and Matthew Bedke (2009; forthcoming). The original version of this chapter was a response to all three authors, under the title "The Metaethical Irrelevance of Evolutionary Theory." However, when I returned to that piece after several years spent working on other projects, I found that I had so much to say about Street's articles, much of it not applicable to Joyce's and Bedke's work, that it no longer made sense to treat all three authors as offering versions of essentially the same argument. I hope on a future occasion to give Joyce's and Bedke's evolutionary arguments the attention they deserve. 
than varieties of normative realism are will allow us to separate the two independent lines of argument in Street's work, and will allow us to recognize which of her explanatory demands are reasonable and which unreasonable. Second, I will be paying close attention to two different dependency relations: the causation relation and the in-virtue-of relation. I do so because I believe Street's first line of argument only looks troubling for her opponents if we ignore the second of these relations. This is ironic, because Street's own explanation of why Humean constructivism avoids that first line of argument involves an appeal to the invirtue-of relation. But if she is allowed to appeal to this relation, then her opponents should be allowed to appeal to it as well. By doing so, normative realists can defuse Street's first line of argument. Of course, they must still contend with Street's second line of argument. But so too, I will argue, must Street.

\section{Street on Realism versus Antirealism}

Street takes her evolutionary argument to refute a metaethical view she dubs "normative realism" and to support a metaethical view she dubs "normative antirealism." However, Street uses these terms in a somewhat idiosyncratic manner, so it is worth pausing to get clear on what, exactly, Street takes the target of her argument to be.

Following Street, let us use the expression "evaluative attitudes" to cover at least the following: "desires," "attitudes of approval or disapproval," "unreflective evaluative tendencies" (such as a tendency to experience fact $\mathrm{F}$ as counting in favor of or as demanding $\phi$-ing), and "consciously or unconsciously held normative judgments" (such as the judgment that $\mathrm{F}$ is a reason for agent $\mathrm{A}$ to $\phi$ in circumstance $\mathrm{C}$ ). ${ }^{2}$ As Street sees it, the realism versus antirealism dispute in metaethics ${ }^{3}$ turns on whether normative facts are grounded in our evaluative attitudes. More precisely, she defines realism and antirealism about

2 See Street 2006, 110; 2008b, 226n3; 2009b, 295n8; and MSb, 39n3. Perhaps a better term for this cluster of attitudes would be "normative attitudes," since many of them concern what is fitting and what is required, not just what is good. (In her 2006, Street uses "evaluative" as the most general term for anything having to do with oughtness, goodness, appropriateness, and so on; in subsequent work, however, she adopts the more standard practice of using the term "normative" to play this role, with one main exception, namely continuing to call the relevant set of attitudes "evaluative attitudes.")

In the literature on the metaphysics and epistemology of intuitions, there is currently a debate over whether an intuition is a type of judgment or rather some other sort of entity, such as an intellectual seeming. (For references, see Pust 2012, §1.) Street's category "evaluative attitude" is wide enough that, whichever way we side in this debate, normative intuitions count as evaluative attitudes.

3 In this chapter I use the term "metaethics" broadly, to cover the second-order investigation of all first-order norms, not just distinctively moral ones and not just those governing action. 
normativity as follows:

normative realism: There are at least some normative facts or truths that hold independently of all our evaluative attitudes.

normative antirealism: There are no normative facts or truths that hold independently of all our evaluative attitudes. ${ }^{4}$

The sort of dependency at issue here is an asymmetric relation of metaphysical dependence between individual facts or truths. ${ }^{5}$ Let $\mathrm{N}$ be some normative fact, such as $[\mathrm{I}$ have reason to $\phi]$, and let A be some attitudinal fact, such as $[\mathrm{I}$ judge that $\mathrm{I}$ have reason to $\phi] .{ }^{6}$ To say that $\mathrm{N}$ depends on $\mathrm{A}$, in the relevant sense, is to say any of the following:

A grounds $\mathrm{N}$.

A makes it the case that $\mathrm{N}$ obtains.

$\mathrm{N}$ obtains in virtue of $\mathrm{A}$.

$\mathrm{N}$ obtains because A obtains.

To say that $\mathrm{N}$ holds independently of $\mathrm{A}$ is to say that $\mathrm{N}$ does not depend, even in part, on $\mathrm{A}$. This variety of dependence should be familiar from discussions of the Euthyphro dilemma. ${ }^{7}$ Socrates asked: is an act

4 See Street 2006, 110; 2008a, 207; 2008b, 208; 2009a, 214; 2009b, 274; and MSb, 2. There are two extra complications that Street occasionally adds to her definitions of realism and antirealism, but which I think we do best to ignore.

First, Street sometimes defines normative realism as the view that there are at least some normative facts or truths that hold independently of all our evaluative attitudes "and what follows, as a logical or instrumental matter, from those attitudes in combination with the non-normative facts," and qualifies her definition of normative antirealism in a similar way (Street 2009b, 274; see also Street 2009a, 214, and MSb, 2). However, there is no need to include this extra conjunct in our definitions of realism and antirealism. The fact $[\mathrm{P}$ follows, as a logical or instrumental matter, from our evaluative attitudes together with the non-normative facts] does not hold independently of the facts about our evaluative attitudes. Therefore the definitions of realism and antirealism without the extra conjunct are logically equivalent to the definitions with the extra conjunct. (Moreover, talk of what "follows, as a logical or instrumental matter," from a set of evaluative attitudes plus the non-normative facts only makes sense given the truth of the metaethical view Street calls "constructivism," so defining antirealism with the additional conjunct threatens to collapse the distinction between antirealism and constructivism, whereas Street intends constructivism to be only one variety of antirealism.)

Second, Street sometimes requires normative realists to hold that at least some of the evaluative-attitude-independent normative truths concern what one has reason simpliciter to do or what one ought simpliciter to do (Street 2008b, 221-25). I think it is a mistake to build this requirement into the definition of normative realism. It is not uncommon for theorists to hold that there exist mind-independent, genuinely normative facts despite there being no facts about what one ought to do, full stop. (To give but one example: consider the view that there are facts about what we objectively ought to do, and facts about what we subjectively ought to do, but no facts about a variety of "ought" that takes into account both objective and subjective considerations.) Even if, ultimately, such views are unsatisfactory, they should not be ruled out of court by terminological decree.

5 Henceforth I write "fact" instead of "fact or truth." Don't read too much into my use of the word "metaphysical" in the phrase "metaphysical dependence"; I am simply using it to flag that the sort of dependence being discussed is not of a causal, conceptual, semantic, or epistemic variety. If you prefer talk of normative dependence, feel free to use that terminology instead.

6 Throughout, I follow Gideon Rosen (2010) in using " $[p]$ " as shorthand for "the fact that p," and I follow Matthew Evans and Nishi Shah (2012) in using "attitudinal fact" as shorthand for "fact about evaluative attitudes."

7 Street identifies the type of dependence at issue in the normative realism/antirealism debate with the type of dependence at 
pious because it is loved by the gods, or is it loved by the gods because it is pious? The modern, secular version of this question becomes: do I have reason to perform some act because my evaluative attitudes favor it, or do my evaluative attitudes favor that act because I have reason to perform it? Or, in other words, is normativity mind-dependent? Are reasons, values, and duties found or created?

There are two main varieties of normative realism: ${ }^{8}$

naturalist normative realism: There are at least some normative facts that hold independently of all our evaluative attitudes, and all of these normative facts are either identical to or entirely grounded in natural facts. ${ }^{9}$

non-naturalist normative realism: There are at least some normative facts that hold independently of all our evaluative attitudes, and at least some of these normative facts are non-natural and ungrounded.

There are two varieties of normative antirealism:

nihilist normative antirealism: There are no normative facts.

non-nihilist normative antirealism: There are at least some normative facts, and all of these normative facts are at least partially grounded in facts about our evaluative attitudes.

According to Street, non-nihilist versions of normative antirealism include Bernard Williams's account of internal reasons, David Lewis's dispositional theory of value, Christine Korsgaard's Kantian constructivism, and her own Humean constructivism. ${ }^{10}$

Using the labels "realism" and "antirealism" to pick out the two sides of this dispute over the mind-dependence of normativity leads - or, at least, threatens to lead - to some surprising taxonomic consequences. In particular, it seems that preference utilitarianism and the combination of ethical egoism and an actual-desire-based theory of well-being both count as antirealist on Street's definition. Consider the following versions of such views (similar points hold for other versions):

issue in the Euthyphro dilemma in her 2009a, 213; 2009b, 274; 2010, 370; 2012, 41; and MSb, 40n8.

8 I say "main" because there are other forms of normative realism beyond these two. For example, a realist view on which every normative fact is at least partially grounded in another normative fact does not count as either naturalist or non-naturalist, by these definitions.

9 In what follows I shall, for ease of exposition, ignore the varieties of naturalist normative realism that take normative facts to be identical to natural facts. Everything I go on to say about versions of naturalism formulated in terms of grounding will apply, mutatis mutandis, to versions of naturalism formulated in terms of identity.

10 Street cites Williams as an antirealist in her 2009b, 295; 2012, 42n6; and MSa, 11-12; she cites Lewis as an antirealist in her 2006, 163n57; 2011, 16, 31; and 2012, 42n6; and she cites Korsgaard as an antirealist in nearly every article she has written. 
preference utilitarianism: Agent A ought to $\phi$ in circumstance $\mathrm{C}$ if and only if, and because, A's $\phi$-ing in $\mathrm{C}$ better serves everyone's preferences than any alternative available to A in C.

actual-desire-based ethical egoism: Agent A ought to $\phi$ in circumstances $\mathrm{C}$ if and only if, and because, A's $\phi$-ing in $\mathrm{C}$ better promotes A's desires than any alternative available to A in C.

The "because" in these formulations picks out the in-virtue-of relation. Thus, according to the former view, [Agent A ought to $\phi$ in circumstance C] is grounded in [A's $\phi$-ing in $\mathrm{C}$ better serves everyone's preferences than any alternative available to A in C], which itself is grounded in facts about everyone's evaluative attitudes (preferences being one form of evaluative attitude). And according to the latter view, [Agent A ought to $\phi$ in circumstances C] is grounded in [A's $\phi$-ing in C better promotes A's desires than any alternative available to $\mathrm{A}$ in $\mathrm{C}]$, which itself is grounded in facts about A's evaluative attitudes (desires being one form of evaluative attitude). It follows that both of these theories qualify as forms of antirealism. ${ }^{11}$ But shouldn't preference utilitarianism and ethical egoism be compatible with realism?

In one way, it is not particularly troubling if Street's use of the labels "realism" and "antirealism" forces us to deem preference utilitarians and ethical egoists to be antirealists. The reason these examples seem to cause trouble for Street's taxonomy is due to the widespread belief that (i) utilitarianism and egoism are positions in normative (i.e. first-order) ethics, (ii) realism and antirealism are positions in meta(i.e. second-order) ethics, and (iii) any position in normative ethics is compatible with just about any position in metaethics (except, perhaps, for metaethical views such as nihilism which entail that there is no such subject as normative ethics). But maybe we should give up on some or all of these assumptions. Maybe some normative ethical views have direct metaethical implications. Maybe mind-dependence is an issue in normative ethics, not metaethics. ${ }^{12}$ And maybe utilitarianism and egoism are best thought of as metaethical positions, or as positions both in metaethics and in normative ethics. In the end, does it matter too much whether a philosophical position falls on one or the other side of the metaethics versus

\footnotetext{
11 I assume here that the grounding relation is transitive. I also assume that these theories either deny that there are any other normative facts beyond the ones within their scope, or ground those other normative facts in the same sorts of considerations that ground facts about what one ought to do (for example, grounding [A is epistemically justified in believing that $p$ ] in facts about everyone's preferences or facts about A's desires; see Kornblith 1993 and Petersen 2013 for views of this sort).

12 As Simon Blackburn, Ronald Dworkin, and Allan Gibbard have all urged. (Street expresses a willingness to concede this point to Blackburn, Dworkin, and Gibbard for the sake of argument in multiple places; see her 2008b, 227n23; 2009a, 215; 2009b, 295n9; 2010, 378; and MSb, 9, 40n8.)
} 
normative ethics divide? Indeed, does it even matter that there be a coherent metaethics versus normative ethics divide? Subdisciplinary taxonomy is not an end in itself.

But there is another, more pressing reason why deeming preference utilitarianism and ethical egoism to be forms of antirealism should trouble Street. Street wants her evolutionary argument for antirealism to have a surprising conclusion. However, if preference utilitarianism and ethical egoism end up being forms of antirealism, in Street's sense, then it will turn out that many naturalists can accept Street's evolutionary argument without worry. Indeed, given that, according to Street (2006, 146-52), experiences of pleasure and pain are best thought of as being constituted by evaluative attitudes, it will turn out that almost all naturalists are untouched by Street's argument, since there are very few naturalists who ultimately ground normative facts in something other than conative states such as desires and experiential states such as pleasure and pain. ${ }^{13}$ Naturalist normative realism will be a position in logical space, but one not occupied by any practicing philosophers.

It is for this reason, I suspect, that Street in effect embraces a second way of responding to the taxonomic puzzle I have raised. ${ }^{14}$ On this approach, we insist that facts about what grounds normative facts themselves count as normative facts. Then whether a given form of preference utilitarianism is a realist or antirealist position will depend on whether the grounding fact [[A ought to $\phi$ in $\mathrm{C}]$ is grounded in [A's $\phi$-ing in $\mathrm{C}$ better serves everyone's preferences than any alternative available to A in C]] is itself grounded in facts about evaluative attitudes. And similarly for forms of ethical egoism that embrace actual-desire-based theories of well-being: they will be compatible with both realism and antirealism, depending on whether a certain grounding fact is itself grounded in facts about evaluative attitudes.

This move saves the debate, but it is not without its costs. I mention here just two. First, it

13 Knut Skarsaune makes a related point in his 2011, 240-41.

14 My evidence that Street embraces this reply is threefold. First, she explicitly states that whether varieties of naturalism formulated in terms of natural-normative identities count as realist or antirealist depends on whether those identities are themselves grounded in attitudinal facts (Street 2006, 135-41; 2008b, 223). The natural extension of this proposal to varieties of naturalism formulated in terms of natural-normative grounding claims is to say that whether such views count as realist or antirealist depends on whether the relevant natural-normative grounding claims are themselves grounded in attitudinal facts. Second, one of Street's ways of replying to a common objection to her evolutionary argument crucially relies on the claim that facts about the grounds of normative facts are substantive normative facts (see $\$ 5$ below). Third, Street's own metaethical view, Humean constructivism, is a proposal about the ultimate grounds of all normative truths (see $\$ 6$ below), and she regularly treats that view as itself a normative truth grounded in the very thing which, according to that view, grounds all normative truths (see Street 2009a, 216n7; 2010, 378, 382n16; MSa, 14-17; and MSb, 36-38). 
commits the antirealist to an infinite hierarchy of grounding facts. For every normative fact $\mathrm{N}$, not only must $\mathrm{N}$ be grounded in at least one attitudinal fact, but that first-order grounding fact must itself be grounded in at least one attitudinal fact, that second-order grounding fact must itself be grounded in at least one attitudinal fact, and so on, ad infinitum. Thus if $\mathrm{A}_{i}$ are all attitudinal facts, we have the following: 15

$$
\begin{aligned}
& {\left[\mathrm{N} \leftarrow \mathrm{A}_{1}\right],} \\
& {\left[\left[\mathrm{N} \leftarrow \mathrm{A}_{1}\right] \leftarrow \mathrm{A}_{2}\right],} \\
& {\left[\left[\left[\mathrm{N} \leftarrow \mathrm{A}_{1}\right] \leftarrow \mathrm{A}_{2}\right] \leftarrow \mathrm{A}_{3}\right],} \\
& \cdots .
\end{aligned}
$$

The existence of such an infinite hierarchy of grounding facts - not groundings "all the way down," 16 but rather groundings "all the way out" - might make some queasy. For instance, we might wonder whether there are enough evaluative attitudes to ground everything in this infinite hierarchy. ${ }^{17}$

A second cost of this move is that Lewis and Williams, two of Street's canonical examples of antirealists, now no longer count as antirealists, in her sense. Lewis can plausibly be read as grounding facts about value in attitudinal facts, and Williams can plausibly be read as grounding facts about reasons for action in attitudinal facts. ${ }^{18}$ But neither Lewis nor Williams can plausibly be read as holding that the fact that value or reason facts are grounded in attitudinal facts is itself grounded in attitudinal facts. ${ }^{19}$

15 Throughout, I use " $F_{1} \leftarrow F_{2}$ " as shorthand for " $F_{1}$ is at least partially grounded in $F_{2}$." (This is a slight variant of Rosen's conventions in his 2010.)

16 Groundings "all the way down" would have the following form:

$\left[\mathrm{N} \leftarrow \mathrm{A}_{1}\right]$,

$\left[\mathrm{A}_{1} \leftarrow \mathrm{A}_{2}\right]$,

$\left[\mathrm{A}_{2} \leftarrow \mathrm{A}_{3}\right]$,

$\cdots$

17 A partial reply to this worry: because we are dealing with groundings "all the way out" and not "all the way down," allowing that $\mathrm{A}_{i}=\mathrm{A}_{j}$ when $i \neq j$ does not commit us, via transitivity, to a fact partially grounding itself. Thus it is open to the antirealist to ground this infinite hierarchy of grounding facts in a finite number of attitudinal facts. (And, as we shall see, this is precisely what Street proposes: for Street, the same attitudinal facts which ground $\left[N \leftarrow A_{1}\right]$ also ground each subsequent fact in our regress. See n. 54 below.)

18 For a contrary interpretation of Williams, see Manne 2014, 106.

19 Given these two costs, some might wonder whether the medicine I have offered Street, and which I believe she herself takes (see n. 14), is worse than the disease. Maybe Street should pursue one of the following strategies instead:

- Insist that facts about the grounds of normative facts are not themselves normative, and try to find a way of rephrasing the definitions of realism and antirealism so that preference utilitarianism and ethical egoism are deemed to be compatible with either realism or antirealism, whereas Lewis's and Williams's views are automatically categorized as antirealist.

- Insist that the because/grounding relation featured in first-order ethical theories is distinct from the because/grounding relation employed in metaethics (and hence in Street's definitions of realism and antirealism), and hold that only facts 
I have gone through this excursus on Street's definitions of realism and antirealism for two reasons. First, it shows just how strong a view Streetian antirealism is. Indeed, I doubt that anyone other than Street has ever defended a non-nihilist version of normative antirealism, in her sense. This makes it all the more impressive if Street's evolutionary argument can show that normative antirealism is true. Second, this excursus establishes what will become a common theme in this chapter: that when evaluating Street's argument, what grounds grounding facts is where most of the philosophical action is.

\section{Street's Darwinian Dilemma for Normative Realists}

Street's evolutionary argument against normative realism starts from the following premise:

the Darwinian hypothesis: Natural selection and other evolutionary factors have had a tremendous influence on the content of our evaluative attitudes.

Given this hypothesis, Street holds that realists must take a stand on the relation between the evolutionary forces that have influenced the content of our evaluative attitudes and the attitude-independent normative truths posited by the realist. This leads to a dilemma for the realist:

first horn (pushing-toward horn): Hold that evolutionary forces have tended to push our normative judgments (and other evaluative attitudes) toward the attitude-independent normative truth.

second horn (at-best-random horn): Hold that evolutionary forces have tended to push our normative judgments (and other evaluative attitudes) either away from or neither away from nor toward the attitude-independent normative truth. ${ }^{20}$

concerning the extension of the former relation count as normative facts.

I am dubious of the assumptions that underlie both of these proposals. (I doubt that facts about the grounds of normative facts are somehow not normative despite entailing the normative facts being grounded, and I doubt that we have two sorts of grounding relation here, one "internal" to first-order ethical theory and the other "external" to it; for more discussion of this second issue, see Berker MSc.) But even if we put my reservations to one side, these two strategies will not succeed in what is presumably their primary aim, which is to avoiding saddling Street with a commitment to an infinite hierarchy of groundings "all the way out." For as we shall see, even if facts about the grounds (or groundsmetaethics) of normative facts are not themselves normative, facts of this sort - because they lack causal powers - will be just as susceptible to Street's Darwinian challenge as normative facts are. Hence if Street's argument for the attitude-dependence of normative facts is sound, a similar argument can establish that facts about the grounds (or grounds metaethics) of normative facts are attitude-dependent, whether or not those facts count as normative. Thus even if antirealism as such is not committed to an infinite hierarchy of groundings "all the way out," the sort of antirealism motivated by Street's evolutionary argument is so committed. (For similar reasons, even if we can find a way of reformulating antirealism so that Williams and Lewis count as antirealists, it will still turn out that Williams's and Lewis's views fall within the target of Street's Darwinian argument, since Williams and Lewis do not take their claims about what certain normative facts depend on to themselves be attitude-dependent claims.) In order to avoid having to distinguish between antirealism as such and the sort of antirealism motivated by Street's evolutionary argument, I will, in what follows, work under the assumption that facts about the grounds of normative facts qualify as normative facts, and under the assumption that the sort of grounding or in-virtue-of talk at issue in metaethics is not distinct from the sort of grounding or in-virtue-of talk at issue in normative ethics.

20 In what follows, I drop the "and other evaluative attitudes" qualifiers in these horns and restrict my discussion to evolution's impact on our normative judgments; parallel issues arise for other types of evaluative attitudes. 
Talk of pushing here is of course metaphorical: the crucial issue is whether evolutionary forces have tended to influence our judgments about reasons, values, duties, and other normative matters in such a way as to make them line up with the attitude-independent facts about such matters. The first horn holds that this is the case; the second horn holds that it is not. ${ }^{21}$

According to Street, the problem with the first horn is empirical (Street 2006, 125-35; 2008b, 209; 2009a, 234-36; 2011, 12-13). Street claims that realists who embrace this horn are forced to endorse the following explanation:

the tracking account: Evolutionary forces have tended to make our normative judgments track the attitude-independent normative truth because it promoted our ancestors' reproductive success to make true normative judgments (or to make proto versions of them).

But Street thinks the tracking account is bad science; she insists that a far more scientifically respectable account — in terms of parsimony, clarity, and degree of illumination — is the following:

the adaptive-link account: Evolutionary forces have pushed us toward making certain normative judgments because (i) making (proto versions of) those judgments made our ancestors more likely to act in accordance with them, and (ii) it promoted reproductive success to act in those ways.

Suppose evolutionary factors are partially responsible for my judging the proposition $<$ I have conclusive reason to $\phi>$ to be true. ${ }^{22}$ Figure 1 shows the sort of dependency structure put forward by the tracking and adaptive-link accounts for the fact that I make this judgment. ${ }^{23}$ The tracking account postulates the existence of normative facts, whereas the adaptive-link account does not, so the tracking account is less parsimonious than the adaptive-link account (Street 2006, 129). The tracking account leaves it mysterious how the truth of certain normative facts could make judgments about the obtaining of those facts reproductively advantageous, whereas the adaptive-link account contains no such obscurities, so the

21 Let us use "EF" as shorthand for "the evolutionary forces that have influenced the content of our evaluative attitudes" and "NT" as shorthand for "the attitude-independent normative truths posited by the realist." In her early work, Street characterizes her dilemma by saying that, on the first horn, the realist "asserts [or affirms] a relation" between EF and NT, whereas, on the second horn, the realist "denies a relation" between EF and NT (Street 2006, 121; 2008, 208-9). I find this way of describing the horns of Street's dilemma unhelpful. In the logician's sense of "relation," there is always a relation between EF and NT: there always exist infinitely many two-place relations that hold between EF and NT. But if we use "relation" in a more restricted sense, then it is far from clear what relation Street means to be picking out. (David Copp makes a similar point in his 2008, 205n9.) Luckily, in her later work, Street clarifies which relation she has in mind, namely the pushing-toward relation I have invoked in my formulation of her dilemma (Street 2008b, 208, 226n4; 2011, 12).

22 Throughout, I use " $\langle p>$ " as shorthand for "the proposition that $p$. "

23 In all figures in this chapter, dashed arrows represent the "tends to (at least partially) cause" relation, and solid arrows represent the "tends to (at least partially) ground" relation. 
tracking account:

$[$ I judge $<$ I have conclusive reason to $\phi>]$

$\triangle$

[Judging $<$ I have conclusive reason to $\phi>$ promoted reproductive success in my ancestors' environment]

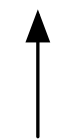

$[$ My ancestors had conclusive reason to $\phi]$ adaptive-link account:

\section{[I judge $<$ I have conclusive reason to $\phi>$ ]}

$\Delta$

1

Judging $<$ I have conclusive reason to $\phi>$ promoted reproductive success in my ancestors' environment]

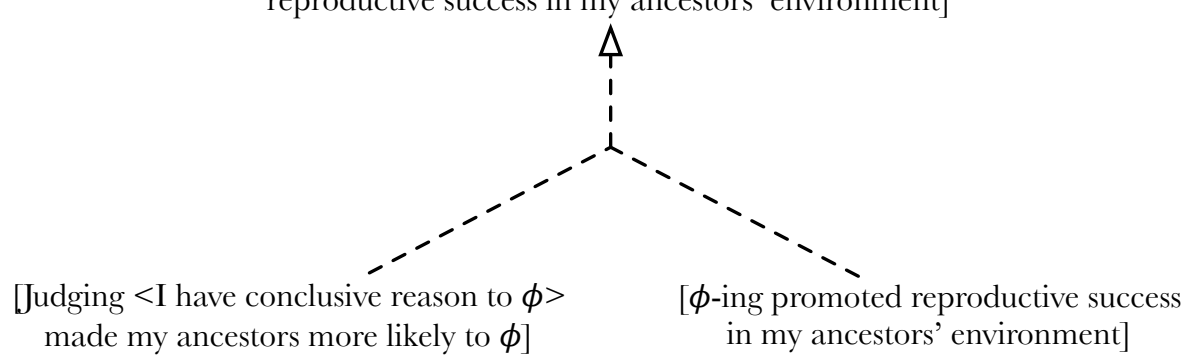

Figure 1. 
tracking account is less clear than the adaptive-link account (Street 2006, 129-32). And, when we look at the full pattern of normative judgments influenced by evolutionary factors, the adaptive-link accounts reveals an illuminating unity to these judgments which the tracking account is unable to detect (Street 2006, 132-34). All told, Street argues, the tracking account does not fare well in comparison to the adaptive-link account, as a purely empirical matter.

So perhaps the realist is better off embracing the second horn of Street's dilemma, according to which evolutionary forces have tended to push our normative judgments in ways that are at best random with respect to the attitude-independent normative truth. Here Street thinks the problem is not empirical but epistemological (Street 2006, 121-25; 2008b, 208-9; 2009a, 233-34; 2011, 13-14). She writes:

As a purely conceptual matter, the independent normative truth could be anything. . . . But if there are innumerable things such that it's conceptually possible they're ultimately worth pursuing, and yet our [normative judgments] have been shaped from the outset by forces that are as good as random with respect to the normative truth, then what are the odds that our [normative judgments] will have hit, as a matter of sheer coincidence, on those things which are independently really worth pursuing? (Street 2011, 14)

Thus on the second horn the realist is forced to embrace the "skeptical conclusion" that "our normative judgments are in all likelihood hopelessly off track" (Street 2008b, 208). Since this horn is just as unpalatable as the first one, and since the realist has no option but to choose one of them, Street concludes that normative realism is false.

Street presents her argument as if it is an argument for normative antirealism. But she does not actually argue against the skeptical conclusion which threatens the realist on the second horn of her dilemma: she simply dismisses this possibility as "implausible" (Street 2006, 109, 122; 2008b, 209; 2011, 14; MSb, 18, 21, 35) or “unacceptable” (Street 2006, 135; 2008b, 211; 2009a, 228, 238; MSa, 11; MSb, 37). This is too quick. Skepticism with regard to normative matters - much like skepticism about other matters (the external world, induction, and so on) - is a legitimate theoretical possibility that must be reckoned with, not casually brushed aside. So really Street's evolutionary argument is for a disjunctive conclusion: either normative antirealism is true, or normative skepticism is true (where the former is a metaphysical thesis about the grounds of normative truths, the latter an epistemological thesis about our inability to know such truths). No matter, though: it would still be an incredibly significant contribution if 
even this disjunctive conclusion could be established. ${ }^{24}$

\section{Complications with the First Horn}

The general thrust of Street's argument is clear, but once we look under the surface, complications arise.

In particular, there are two problems with the pushing-toward horn of Street's dilemma. ${ }^{25}$

First problem: the adaptive-link account is inadequate as it stands. As applied to the proposition

$<$ I have conclusive reason to $\phi>$, the adaptive-link account starts by assuming a version of motivational internalism (Street 2006, 157n13; 2008a, 228n37, 230; 2010, 376):

(MI) Necessarily, if an agent judges $<$ I have conclusive reason to $\phi>$, then she is at least somewhat motivated to $\phi .{ }^{26}$

Then the thought is that if $\phi$-ing promoted reproductive success in our ancestors' environment, those of our ancestors who judged $<\mathrm{I}$ have conclusive reason to $\phi>$ did better at propagating their genes than those who didn’t. However, this explanation is not fully satisfactory. First, to apply the adaptive-link account across the board, we need a version of motivational internalism to hold with regard to every normative proposition. But it is far from clear that all normative claims have a distinct necessarilyaccompanying motivational shadow. For example, consider the following propositions:

$<$ I have a reason to $\phi$, but it is heavily outweighed by other considerations $>$;

$<$ I am permitted but not required to $\phi>$;

24 At times Street gestures toward what might seem to be an argument against normative skepticism, when she claims that "one must reject [normative skepticism] if one is to go on making normative judgments at all" (Street MSb, 35; see also Street 2010, 383n60, and 2011, 16). However, this is not an argument against the truth of normative skepticism; rather, it is an argument against the rational coherence of accepting normative skepticism while continuing to make normative judgments.

25 There are also problems with the at-best-random horn, but I pass them over on this occasion. First issue: does Street think our normative judgments fail to be justified or to constitute knowledge if they in fact do not track the normative truth, or do they only fail to be justified or to constitute knowledge if we realize that our normative judgments do not track the normative truth? Second issue: what exactly is this tracking relation? The textual evidence suggests that Street takes the relevant tracking relation to be a Nozick-style sensitivity condition (if it were false that $p, \mathrm{~S}$ would not judge that $p$ ), but where instead of evaluating the relevant subjunctive conditional in terms of metaphysically possible worlds, as is customary, we instead evaluate it in terms of conceptually possible worlds. (Presumably this last bit is to avoid the consequence that judgments about metaphysically necessary propositions automatically satisfy the tracking requirement, since subjunctive conditionals with impossible antecedents are trivially true.) But requiring our judgments to satisfy such a constraint in order to be justified or in order to constitute knowledge leads to deeply counterintuitive consequences: some of these consequences are the familiar ones that bedevil all sensitivity views, and some of these consequences are new ones arising from the appeal to conceptual possibility. I hope to discuss these matters in greater detail in future work.

26 Street stresses the importance of motivational internalism for the adaptive-link account, but in fact even motivational externalists can endorse a version of the adaptive-link account, as long as they hold that judging $<\mathrm{I}$ have conclusive reason to $\phi>$ is highly correlated in the actual world with being at least somewhat motivated to $\phi$. 
$<$ In virtue of $[p]$, I have conclusive reason to $\phi>.27$

Second, the adaptive-link account leaves it mysterious why we didn't evolve merely to have the relevant motivations on their own, without any accompanying normative judgments. If the only evolutionary value of normative judgments are their motivational effects, wouldn't it have been much cheaper for evolutionary forces to instill in us those motivational effects by themselves without any accompanying judgments (or proto judgments)? ${ }^{28}$

I am not denying that there is an acceptable evolutionary explanation of our tendency to make certain normative judgments. I am not even denying that the mechanisms highlighted by the adaptive-link account could play an important role in this more complete explanation. ${ }^{29}$ My point, rather, is that the more complete evolutionary explanation will lack the beguiling simplicity of the adaptive-link account.

The second problem with the pushing-toward horn of Street's dilemma is more serious: Street's argument for why realists who embrace this horn must accept the tracking account rests on an equivocation. Here is what Street says:

The only way for realism both to accept that [our evaluative] attitudes have been deeply influenced by evolutionary causes and to avoid seeing these causes as distorting is for it to claim that these causes actually in some way tracked the alleged independent truths. There is no other way to go. To abandon the tracking account . . . is just to adopt the view that selective pressures either pushed us away from or pushed us in ways that bear no relation to these [normative] truths. (Street 2006, 134-35)

But this passage uses the label "tracking account" in a broader way than Street uses it elsewhere. In these sentences Street is understanding the tracking account as follows:

tracking account (in the broad sense): Evolutionary forces have tended to make our normative judgments track the attitude-independent normative truth.

In contrast, when she first introduces the tracking account (Street 2006, 125-26), and when she argues

27 Why the first of these is problematic: it's one thing to claim that an agent's motivations must reflect her all-thingsconsidered verdicts about her reasons, but quite another to claim that every single judgment about an overridden pro tanto reason must have a motivational residue. Why the second of these is problematic: motivation's scalar structure does not map well onto non-scalar categories such as the merely permitted. Why the third of these is problematic: if the adaptive-link account explains why we evolved to have a tendency to judge $<$ In virtue of [ $p]$, I have conclusive reason to $\phi>$ in addition to having a tendency to judge $\langle p$, and I have conclusive reason to $\phi>$, then the motivational profile of the former must be different from the motivational profile of the latter. But it is not clear that they are. (Note that parallel problems arises even for versions of the adaptive-link account formulated in terms of motivational externalism: the motivational profiles here need not be necessary ones.)

28 Michael J. Deem makes a similar point in his 2012. See also Parfit 2011, 2:527-28.

29 For example, maybe we can make Street's adaptive-link account more empirically adequate by appending to it an account which appeals to Allan Gibbard's idea of normative governance, according to which our linguistically infused normative judgments have a tendency to influence each other's normative judgments through discussion and avowal. See Gibbard 1990, ch. 4. 
that it is scientifically unacceptable (Street 2006, 126-34), Street understands the tracking account more narrowly:

tracking account (in the narrow sense): Evolutionary forces have tended to make our normative judgments track the attitude-independent normative truth because it promoted our ancestors' reproductive success to make true normative (proto) judgments. ${ }^{30}$

According to the first horn of the Darwinian dilemma, evolutionary forces have tended to push our normative judgments toward the attitude-independent normative truth. If we take "pushing our normative judgments toward the normative truth" to be equivalent to "making our normative judgments track the normative truth," then this horn does indeed entail the broad tracking account - does indeed entail that evolutionary forces have tended to make our normative judgments track the attitudeindependent normative truth. But this entailed fact is compatible with any number of stories concerning in virtue of what evolutionary forces have tended to make our normative judgments track the attitudeindependent normative truth. The narrow tracking account is only one of those many stories. ${ }^{31}$

Therefore Street has not successfully shown that the first horn forces realists to accept a tracking account in the narrow sense, which is what she needs for her argument to go through. We can formulate this problem as a dilemma: either we understand the tracking account in the broad sense, in which case Street has not provided an argument that the tracking account is scientifically unacceptable, or we understand the tracking account in the narrow sense, in which case Street has not established that realists who take the first horn of her dilemma must endorse the tracking account. Either way, Street's first horn requires sharpening before it can impale the realist. ${ }^{32}$

30 In fact, sometimes Street understands the tracking account more narrowly still:

tracking account (in the even more narrow sense): Evolutionary forces have tended to make our normative judgments track the attitude-independent normative truth because it promoted our ancestors' reproductive success to make true attitude-independent normative (proto) judgments.

Street uses "tracking account" to pick out the narrow tracking account in her 2006, 109, 125-28, 129-34, 151; 2009a, 240, 242; and 2011, 13; and she uses "tracking account" to pick out the even-more-narrow tracking account in her 2006, 129, 141, 151, 154; 2008b, 209-10; 2009a, 234, 241; and 2011, 12, 13. The only place where Street uses "tracking account" to pick out the broad tracking account is in the one place where she explicitly argues that realists who embrace the first horn of her Darwinian dilemma must endorse the tracking account, in her 2006, 134-35.

31 Copp makes a similar point, when he distinguishes between what he calls "the tracking thesis" and "the tracking account" (Copp 2008, 194-95).

32 In her 2008b, 209, 211, Street seems to recognize that a narrow tracking account is not the only option on the first horn of her Darwinian dilemma. However, in her 2009a, 234, and 2011, 12-13, she goes back to saying that a narrow tracking account is the only option on that horn. 


\section{The Third-Factor Response}

One popular way of resisting Street's Darwinian dilemma is to exploit the opening left by the second problem I have just mentioned for its pushing-toward horn. The typical way of doing this is to offer, instead of a narrow tracking account, an explanation of the following form:

a third-factor account: Evolutionary forces have tended to make our normative judgments track the attitude-independent normative truth because, for each normative judgment influenced by evolution in this way, there is some third factor, F, such that

(i) F tends to causally (help) make it the case that (proto) judging in that way promotes reproductive success (when in our ancestors' environment), and

(ii) F tends to metaphysically (help) make it the case that the content of that judgment is true. ${ }^{33}$

The first person to offer a third-factor account in response to an argument much like Street's was Robert

Nozick, who in his 1981 book Philosophical Explanations wrote:

The ethical behavior will serve inclusive fitness through serving or not harming others, through helping one's children and relatives, through acts that aid them in escaping predators, and so forth; that this behavior is helpful and not harmful is not unconnected to why (on most theorist[s'] views) it is ethical. The ethical behavior will increase inclusive fitness through the very aspects that make it ethical, not as a side effect through features that only accidentally are connected with ethicality. (Nozick 1981, 346)

Third-factor accounts of various forms have also been offered by Kevin Brosnan (2011), David Copp (2008), David Enoch (2010), Knut Skarsaune (2011), and Erik Wielenberg (2010). ${ }^{34}$

As I see it, there are two basic thoughts behind third-factor accounts. The first is that we don't, in general, need to posit a direct dependency relation between a judgment that $p$ and the fact that $p$ in order to explain why it is not a cosmic coincidence that the former tracks the latter. Certainly a direct dependency relation will do: if my judgment that $p$ is caused by the fact that $p$, or if my judgment that $p$ causes the fact that $p$, then it is no mystery why judgment tracks fact. But this is not the only option. For example, a common-cause structure will suffice as well. Suppose you intend to stay home sick tomorrow and tell me so; as a result, I judge that you will stay home sick tomorrow. When tomorrow you do in fact stay home, it is no mystery why my judgment that you would tracked the truth, but in this case we do not

33 I assume here, for convenience, that facts are among the causal relata. If you think that, say, only events can be causes and effects, feel free to reformulate everything I say accordingly.

34 These authors all offer third-factor accounts as ways of defending realism against Street's evolutionary challenge. Simon Blackburn (MS) and Jamie Dreier (2012; see esp. p. 283) in effect offer third-factor accounts as ways of defending quasi-realism against Street's challenge. The label "third-factor account" originates, I believe, in Enoch 2010. 
a third-factor account:

[I judge $<$ I have conclusive reason to $\phi>$ ]

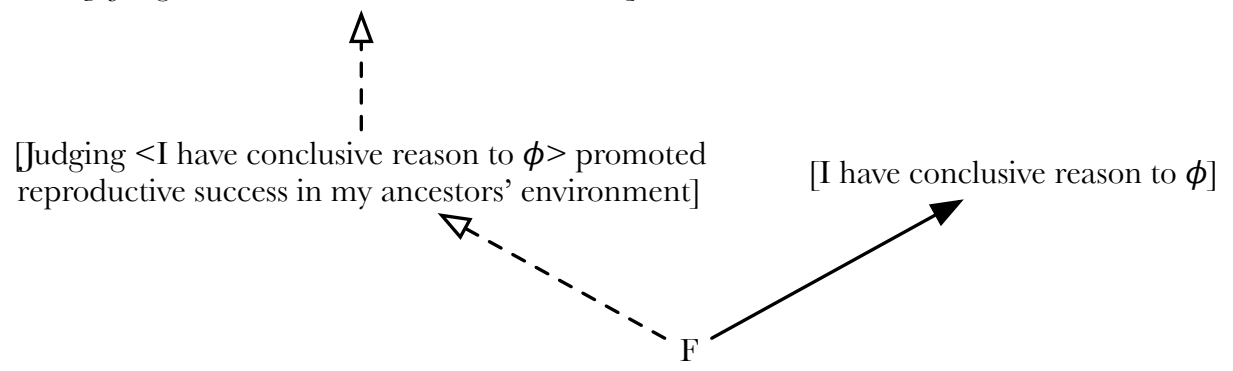

Figure 2.

have a direct causal link: my judgment did not cause you to stay home (I don't have this much influence on you, alas), and your staying home did not cause my judgment the day before (no backwards causation here). Rather, a common-cause structure explains the tracking relation between judgment and fact: your intention to stay home both caused my judgment and caused the content of that judgment to be true. ${ }^{35}$

The second thought behind third-factor accounts is that, when explaining why a given judgment tracks a given fact, any sort of a dependency relation is enough: we need not restrict ourselves to the causation relation. In particular, the grounding relation (and its converse, the in-virtue-of relation) will do. Thus in order to explain why my judgment that $p$ tracks the fact that $p$, we can take a common-cause structure and swap in the grounding relation for one of the two causal relations. What results, when $<p>$ is normative, is a third-factor account (see Figure 2): we posit some non-normative third fact on which my judgment that $p$ causally depends and on which the fact that $p$ metaphysically depends. Doing so allows us to explain tracking relations between normative facts and normative judgments, without taking normative facts to have causal powers.

Several comments about third-factor accounts are in order. First, there is no need, in a thirdfactor account, to hold that the third factor entirely grounds the relevant normative fact; a relation of partial grounding is enough. After all, in more mundane cases in which one explains why a non-normative judgment tracks a non-normative fact by appealing to a direct causal relation between judgment and fact,

35 I assume here, for illustrative purposes, that an intention causes (rather than partially constitutes) its corresponding action. 
there is no need for the fact to cause the judgment entirely on its own, or for the judgment to cause the fact entirely on its own; partial causation is, in most cases, enough. (Hence the "help" qualifiers in my formulation of third-factor accounts.) Second, given that the sort of tracking at issue here is not perfect tracking, but rather fairly good tracking, we need not postulate that our third factor, when present, always causes the judgment in question and always grounds the fact judged to obtain; a strong enough tendency to cause the judgment and to ground the fact will do. (Hence the appeal to tendencies in my formulation of third-factor accounts.) Third, once we grasp the general idea behind third-factor accounts, we can see that really they are a template for a whole host of different accounts that posit a complex dependency structure involving both causal and grounding links. For example, depending on how the evolutionary facts pan out, it may well be more plausible to posit the following instead of a strict third-factor account:

a fourth-factor account: Evolutionary forces have tended to make our normative judgments track the attitude-independent normative truth because, for each normative judgment influenced by evolution in this way, there is some factor, $\mathrm{F}$, and some factor, $\mathrm{F}^{*}$, such that

(i) F tends to causally (help) make it the case that (proto) judging in that way promotes reproductive success (when in our ancestors' environment),

(ii) $\mathrm{F}^{*}$ tends to metaphysically (help) make it the case that the content of that judgment is true, and

(iii) $\mathrm{F}$ and $\mathrm{F}^{*}$ stand in a suitable causal relation with one another (where identity is treated as the limiting case of a causal relation).

This proposal involves adding intricacies to the causal side of a third-factor account. We might also, in addition, complicate the normative end of things. For instance, we might posit that our fourth factor, $\mathrm{F}^{*}$, (tends to) partially ground a normative fact which (tends to) stand in various partial grounding relationseither upwards or downwards - with the normative fact being judged to obtain. ${ }^{36}$ (A fifth-factor account?) And so on: the possibilities are legion. ${ }^{37}$

Thus third-factor accounts, and others of their ilk, represent an extremely versatile way of embracing the first horn of Street's dilemma without resorting to a narrow tracking account. This

36 Enoch $(2010,431)$ also broaches the possibility of a broadly third-factor account with this sort of structure.

37 There are difficult questions here about exactly which dependency structures of the sort I have sketched are sufficient to underwrite a tracking relation between judgment and fact. How complicated can we make the overall dependency structure, and how tight must each link in that dependency structure be? Taking a stand on these issues, however, would require us to give a substantive account of what tracking comes to, and that is not a task I have undertaken in this chapter. (See n. 25 above.) Note, also, that these difficult questions arise even when we have a purely causal dependency structure underwriting a tracking relation; they are not unique to dependency structures involving both causal and grounding links. 
versatility explains, I believe, why so many authors have - apparently independently — hit upon this way of replying to Street. Indeed, if you don't think that normative facts have causal powers, a third- (or fourth-, or ... ) factor account of how our normative judgments track the normative truth despite being heavily influenced by evolutionary forces is almost inevitable.

But this is not the end of the story, for we can find in Street's work two very powerful objections to third-factor accounts. ${ }^{38}$ According to the first of these objections, Street can simply re-run her Darwinian dilemma "one level up." 39 The third-factor theorist relies on at least one claim of the following form:

(G) Non-normative fact $\mathrm{F}$ (at least partially) grounds normative fact $\mathrm{N}$.

Being a realist, the third-factor theorist presumably thinks that $(G)$ 's truth does not depend on any facts about our evaluative attitudes. ${ }^{40}$ But now we can ask: how does the third-factor theorist know that $(\mathrm{G})$ is true? Whatever method we use to judge that $(\mathrm{G})$ is true (whether it be reflective equilibrium or some other method) is, no doubt, greatly saturated with evolutionary influences. And this raises the familiar question: what, according to the realist who resorts to a third-factor response, is the relation between the evolutionary forces that have influenced our judgment that $(G)$ is true and the evaluative-attitude-independent fact that $(G)$ is true? On the one hand, if evolutionary forces have tended to push us toward making a correct verdict about $(\mathrm{G})$ 's truth, then - Street would insist - the only explanation open to the realist of why this is so is a tracking account, which loses out to the more scientifically acceptable adaptive-link account. On the other hand, if evolutionary forces have tended to push us in ways that are at best random with respect to the truth of $(G)$, then - Street would insist - we are in all likelihood wrong in judging $(G)$ to be true. In other words, the

38 Henceforth I use "third-factor account" as a general term encompassing third-factor accounts, fourth-factor accounts, and all others of that sort.

39 See Street 2006, 135-41. Street explicitly formulates the objection to be considered as an objection to versions of naturalist normative realism that are framed in terms of natural-normative identities. However, a similar objection can be offered against versions of naturalist normative realism framed in terms of grounding relations between natural and normative facts, and this latter objection is easily extended into an objection against all third-factor accounts.

40 Actually, there is a problem for Street here. Strictly speaking, a normative realist might hold that $\mathrm{N}$ is not grounded in any attitudinal facts, even though $(\mathrm{G})$ - a fact about what grounds $\mathrm{N}$ - is itself grounded in attitudinal facts. (In general, it is not true that if $F_{1}$ partially grounds the fact $\left[F_{2}\right.$ partially grounds $\left.F_{3}\right]$, then $F_{1}$ partially grounds $F_{3}$.) So Street is not entitled to the assumption she needs to get this objection running, namely that the realist must deem $(\mathrm{G})$ to be attitude-independent. (A similar problem arises for the version of this objection directed against varieties of naturalist realism formulated in terms of identity, since in general it is not true that if $\mathrm{F}_{1}$ partially grounds the fact $\left[\mathrm{F}_{2}=\mathrm{F}_{3}\right]$, then $\mathrm{F}_{1}$ partially grounds $\mathrm{F}_{3}$.) But even though $\mathrm{I}$ believe there is a problem here, I shall ignore it in what follows. The form of normative realism that Street overlooks when offering her objection is extremely recherché, and it would be better if third-factor theorists could provide their reply to Street without committing themselves to such an unusual view. 
third-factor theorist is caught in a Darwinian dilemma, one level up. ${ }^{41}$

Street's second powerful objection to third-factor accounts rests on the charge that such accounts are "trivially question-begging" (Street 2008b, 214-17; 2011, 17-19; MSb, 17-30). Here is how Street puts the point, in response to Copp's version of a third-factor account:

It is no answer to [the Darwinian] challenge simply to assume a large swath of substantive views on how we have reason to live ... and then note that these are the very view evolutionary forces pushed us toward. Such an account merely trivially reasserts the coincidence between the independent normative truth and what the evolutionary causes pushed us to think; it does nothing to explain the coincidence. (Street 2008b, $14)^{42}$

Does Street's objection here mean that, when it comes to truths of other sorts, we are also prohibited from appealing to substantive truths of that sort when explaining how we were selected, either directly or indirectly, to track those truths? And wouldn't such a ban lead to universal skepticism — not just skepticism about our ability to track facts about reasons (if normative realism is true), but also skepticism about our ability to track tables, chairs, and all other mind-independent entities? Not so, says Street. She distinguishes two sorts of explanations we might give as to why evolutionary forces have made us track truths about the presence of midsized objects in our immediate environment:

Account A: There are six chairs, a laptop, and a table in my immediate environment. But evolutionary forces gave rise to the capacity I used to make this very judgment. This gives me reason to think my capacity about midsized objects in my immediate environment is reliable.

Account B: Midsized objects in our immediate environment are the kinds of things one can run into, be injured by, eat, and be eaten by. Other things being equal, then, creatures with an ability accurately to detect midsized objects in their immediate environment tended to survive and reproduce in greater numbers than creatures who lacked this ability. I am a product of this evolutionary process. This gives me reason to think my capacity to make judgments about midsized objects in my immediate environment is reliable. (Street 2008b, 216-17; cf. Street 2011, 19, and MSb, 25)

Street concedes that there is a sense in which Account B is question-begging, since many of its claims (that

41 Note that although it is natural to assume that $(\mathrm{G})$ is normative when offering a "one level up" objection against it, the objection in question does not actually depend on the assumption that $(G)$ is normative. Rather, all it relies on (in addition to the assumption that $(\mathrm{G})$ is attitude-independent; see previous footnote) is the assumption that $(\mathrm{G})$ does not stand in causal relations with other facts, which is independently plausible even if $(G)$ is non-normative. Similarly, even though third-factor theorists usually appeal to a version of $(G)$ in which the relevant grounding relation is the sort employed in first-order ethical theories, Street's "one level up" objection applies just as much to versions of $(\mathrm{G})$ in which the grounding relation is of a distinctively metaethical sort, since - if there is such a relation - facts about its extension do not have causal powers. (This is why I said in n. 19 that neither the strategy of denying that facts about the grounds of normative facts are normative nor the strategy of distinguishing between an "internal" normative-ethical grounding relation and an "external" metaethical grounding relation will avoid committing Street to an infinite hierarchy of groundings "all the way out.")

42 Note that, in offering this reply to third-factor theorists, Street is assuming $(G)$ to be a substantive normative view. This is my second piece of evidence, mentioned in $\mathrm{n} .14$ above, that Street takes facts about the grounds of normative facts to be normative. 
midsized objects in our immediate environment can injure and eat us, that evolutionary processes occur in the world around us, and so on) are ones we came to believe partly through use of our faculties for making judgments about the presence of midsized objects in our immediate environment. Nevertheless, Street maintains, there is an epistemic contrast between A and B: Account B is, according to Street, ultimately question-begging but still gives us good reason to think we're reliable on these matters, whereas Account A is trivially question-begging and gives us no reason to think we're reliable. Moreover, Street insists that third-factor accounts are of the same form as Account A.

Thus things do not look good for the normative realist. At first it seemed that third-factor accounts would present the realist with a promising way of grasping the pushing-toward horn of Street's dilemma without committing to a scientifically indefensible (narrow) tracking account of the relation between evolutionary forces and the attitude-independent normative truth. But now we have seen two formidable objections to third-factor views: they appear to be susceptible to a version of Street's dilemma one level up, and they appear to question-beggingly assume the very thing they aim to show.

In fact I do not think that matters are nearly so dire for the realist. But before I argue why this is so, it will help to take a detour through Street's explanation of why her own metaethical view avoids the Darwinian dilemma.

\section{Street's Solution to the Darwinian Dilemma}

According to Humean constructivism, Street's preferred variety of antirealism,

$\left(\mathrm{G}^{\prime}\right) \quad$ The non-normative fact $[$ A judges $<\mathrm{I}$ have conclusive reason to $\phi>$, and her $\phi$-ing does not conflict with anything else she more deeply judges that she has reason to do] grounds the normative fact $[\mathrm{A}$ has conclusive reason to $\phi] .{ }^{43}$

43 See Street 2008a, esp. 234-36. $\left(\mathrm{G}^{\prime}\right)$ follows, by the transitivity of the grounding relation, from two more specific claims that Street makes:

$\left(\mathrm{G}^{\prime \prime}\right) \quad$ [A judges $<\mathrm{I}$ have conclusive reason to $\phi>$, and her $\phi$-ing does not conflict with anything else she more deeply judges that she has reason to do] grounds [A's judgment $<\mathrm{I}$ have conclusive reason to $\phi>$ withstands scrutiny from the standpoint of A's other normative judgments].

$\left(\mathrm{G}^{\prime \prime \prime}\right) \quad[\mathrm{A}$ 's judgment $<\mathrm{I}$ have conclusive reason to $\phi>$ withstands scrutiny from the standpoint of A's other normative judgments] grounds [A has conclusive reason to $\phi$ ] .

Note that $\left(\mathrm{G}^{\prime}\right)$ is not the only way in which, for a Humean constructivist, non-normative facts about evaluative attitudes can ground normative facts about reasons. For example, Street is also committed to 
How does such a view avoid the Darwinian dilemma? In fact, we find in Street's work two different explanations of why antirealists such as the Humean constructivist can meet her evolutionary challenge. The first of these I call the grounding account, and the second I call the theoretical-reasoning account. ${ }^{4}$

According to the grounding account, our judgments about our reasons tend to track the truth about what reasons we have because the former is what grounds the latter. ${ }^{45}$ Suppose $\left(\mathrm{G}^{\prime}\right)$ is true, and suppose A's judgments about what she has conclusive reason to do don't conflict too greatly with one another. It follows that A's judgments about what she has conclusive reason to do are mostly true, and hence she is not "hopelessly off track" in making such judgments. Moreover, this will be so regardless of the evolutionary story we tell about A's tendency to make judgments of this sort: given any causal story "upstream" in the order of explanation from the judgments themselves, A's judgments about what she has conclusive reason to do will - cases of conflict aside - make themselves true "downstream" in the order of explanation. In other words, if Humean constructivism is correct, then our judgments about our own reasons mostly track the truth, because they serve as the ground of their own truth. Thus the Darwinian dilemma is avoided, at least with respect to such normative judgments.

There is, however, a major problem with the grounding account. Focus on our hypothetical character A again. Humean constructivism plus the grounding account provides a nice explanation of why A's judgments about her own reasons mostly track the truth. However, A's judgments about her own

$\left(\mathrm{G}^{*}\right) \quad[$ A judges $<\mathrm{I}$ have conclusive reason to $\phi>, \psi$-ing is a necessary means to $\phi$-ing, and A's $\psi$-ing does not conflict with anything else she more deeply judges that she has reason to do] grounds [A has conclusive reason to $\psi$ ].

According to the Humean constructivist, the ultimate grounds of a person's reasons are always of the sort found in $\left(\mathrm{G}^{\prime}\right)$ and $\left(\mathrm{G}^{*}\right)$ : they concerns that person's judgments about her reasons, how deeply those judgments are held, and the instrumental connections between the actions (or attitudes) which the person judges that she has reason to perform (or hold). So for illustrative purposes I will simply work with $\left(\mathrm{G}^{\prime}\right)$ in the body of the text.

44 In her early work, Street tends to stick to the grounding account: see, in particular, Street 2006, 153-54, where she explicitly states that the grounding account is the official explanation of why antirealists escape the Darwinian dilemma. In her more recent work, however, Street slides back and forth between the grounding and theoretical-reasoning accounts (sometimes on the very same page): see Street 2011, 22n41, and MSb, 12, for endorsements of the grounding account, and see Street 2011, 16 , and MSb, 12, 30, for endorsements of the theoretical-reasoning account.

45 A qualification here is in order. Sometimes Street says that the normative truth obtains in virtue of (i.e. is grounded in) the facts about our judgments about reasons (as she does throughout Street MSa), and other times she says that the normative truth is constituted by the facts about our judgments about reasons (as she does throughout Street 2008a). I think it is a live issue whether the grounding relation is identical to the constitution relation. But even if they are distinct relations, this has no bearing on any of the claims I make in this chapter: at any point in my argument, we can replace mention of the grounding relation with mention of the constitution relation, whether in my discussion of Street's own view or in my discussion of her third-factor opponents. Constitution, like grounding, is a non-causal form of dependence, so it can play the same role that grounding does in any of these accounts. (Similar comments apply to other non-causal forms of dependence, such as reduction, if that is something distinct from grounding, constitution, and identity [whether synthetic or analytic].) 
reasons are just a tiny subset of her judgments about reasons: presumably she also makes a vast number of judgments about other people's reasons. But the same story cannot be told about why these other judgments tend to track the truth, since the truth of A's judgments of these other sorts depend, according to Street, on other people's normative judgments. From A's perspective, the truth about what other people have reason to do is a mind-independent matter - independent, that is, of A's mind. However, the grounding account only applies to those of A's judgments whose truth is dependent on A's mind. So the grounding account, on its own, is unable to explain why A's judgments about other people's reasons tend to track the truth. ${ }^{46}$

Here is another way of putting the point. Humean constructivism posits a fundamental disunity among A's normative judgments. When it comes to A's normative judgments about her own reasons, thinking making it so (cases of conflict aside). But when it comes to A's judgments about other people's reasons, thinking does not make it so (even when $\mathrm{A}$ is unconflicted)- judgments of that sort do not possess the magic property of ensuring their own truth. And it is precisely this magic property which plays a central role in the grounding account. Thus, from the perspective of the grounding account, the Humean constructivist is no better off than the normative realist when it comes to explaining why A's judgments about other people's reasons tend to track the truth. ${ }^{47}$

This problem was obscured by Street's talk of "our" evaluative attitudes in her formulation of antirealism. Once we see that this pronoun must be used in a distributive (rather than a collective) sense for the grounding account to work in the case of one's judgments about one's own reasons, we can see that this problem is perfectly general, applying to all antirealist theories that attempt to make use of the grounding account in order to avoid the Darwinian dilemma. ${ }^{48}$

An obvious reply suggests itself. Perhaps the evolutionary factors in virtue of which I tend to make the judgments I do about your reasons also make it the case that you tend to make similar judgments

46 In fact, the same point applies to A's judgments about her own past and future reasons, since Humean constructivism ties the truth about one's reasons at a given time to one's judgments at that time about one's reasons at that time.

47 After writing this chapter I discovered that Matthew Chrisman makes a somewhat similar point in his 2010, 338-39, although here Chrisman is discussing whether Street's constructivism can account for ethical knowledge, not whether it can avoid the Darwinian dilemma via the grounding account.

48 The objection I have just pressed against the grounding account reveals another class of normative propositions, beyond the ones I mentioned in $\S 4$, that Street's adaptive-link account is ill-equipped to handle on its own, namely propositions about other people's reasons. My judging that you have conclusive reason to $\phi$ does not entail that I am at least somewhat motivated to $\phi$. (It might, however, entail that I am at least somewhat motivated to help you $\phi$, to praise you for $\phi$-ing, and so on.) 
about your own reasons. This causal hypothesis, together with $\left(\mathrm{G}^{\prime}\right)$, could then be used to explain why my judgments about your reasons mostly track the truth. However, this reply is unconvincing. First, it requires the Humean constructivist to posit a level of convergence in our judgments about reasons that seems incompatible with the existence of persistent normative disagreements. Second, and more seriously, this response does not help explain why our judgments about the reasons of people who do not share our evolutionary history are generally reliable (including many of the judgments that Street herself makes about the reasons of various hypothetical figures during the course of her arguments both against normative realism and for Humean constructivism). In the end, I think there is no way around this problem for the grounding account. ${ }^{49}$

It is perhaps because she recognizes this problem for the grounding account that, in more recent work, Street sometimes provides a quite different account of how antirealists such as the Humean constructivist are able to avoid the Darwinian dilemma. On this account, rather than us, as theorists, appealing to the truth of $\left(\mathrm{G}^{\prime}\right)$ in order to explain why a given agent's judgments about reasons mostly track the truth, instead we imagine that our agent knows the truth of $\left(\mathrm{G}^{\prime}\right)$ and uses it in her deliberations to reason her way to the correct theoretical verdict about what both she and other people have reason to do. Since we are assuming that facts about people's normative judgments are purely non-normative facts, our agent's judgment $<\mathrm{A}$ judges $<\mathrm{I}$ have conclusive reason to $\phi>$, and her $\phi$-ing does not conflict with anything else she more deeply judges that she has reason to do $>$ is not the sort of judgment that, according to Street, is susceptible to a Darwinian dilemma. So our agent can use her knowledge of this proposition and her knowledge of $\left(\mathrm{G}^{\prime}\right)$ to reason her way to judgments about the normative proposition $<\mathrm{A}$ has conclusive reason to $\phi>$ which track the truth, regardless of whether $\mathrm{A}$ is the deliberator herself or someone else.

49 There is an additional problem for the grounding account beyond the main one mentioned in the text. Presumably in order to address the epistemological threat that evolutionary considerations present, it is not enough to show that our normative judgments track the truth: we also want those judgments to constitute knowledge. However, the sort of tracking relation that we get from the grounding account seems irrelevant to knowledge. Consider the proposition <There are beliefs $>$. Whenever I believe this proposition, I make it true, and hence my belief in this proposition tracks the truth in the sense we have been considering here. However, it does not follow that whenever I believe that there are beliefs, I know that there are beliefs, for I might believe that there are beliefs for utterly idiotic reasons. State-given tracking of the sort featured both in this example and in the grounding account does not seem to be the right sort of tracking relation to underwrite knowledge. 
Thus the theoretical-reasoning account avoids the previous problem for the grounding account, and perhaps for this reason is to be preferred. However, the theoretical-reasoning account faces a serious problem of its own. ${ }^{50}$ This is not so much a problem for the account itself, as it is a problem for Street's claim that only antirealists can make use of this account as a way of avoiding her Darwinian dilemma. What makes $\left(\mathrm{G}^{\prime}\right)$ a distinctively antirealist claim is its grounding of a normative fact in the truth of some fact about our evaluative attitudes - in this case, the evaluative attitude of making a judgment about one's own reasons. But the theoretical-reasoning account doesn't in fact rely on this feature of $\left(G^{\prime}\right)$. All that matters for the theoretical-reasoning account are two things: that $\left(G^{\prime}\right)$ itself is knowable, and that $\left(G^{\prime}\right)$ grounds a normative fact in some fact which we can use normal empirical means to ascertain. As far as the theoretical-reasoning account goes, the crucial issue isn't whether $\left(\mathrm{G}^{\prime}\right)$ makes [A has conclusive reason to $\phi]$ mind-dependent, but rather whether it makes that fact knowably dependent on something empirically knowable. Whence, then, Street's claim that antirealism is the only non-skeptical way of avoiding her dilemma?

Here a comparison with third-factor accounts is particularly revealing. Recall that the most basic version of a third-factor accounts involves us, as theorists, appealing to the truth of

(G) Non-normative fact $\mathrm{F}$ (at least partially) grounds normative fact $\mathrm{N}$

in order to explain why a given agent's judgment about $\mathrm{N}$ tends to track the truth. Thus the realist's thirdfactor account is very close to the antirealist's grounding account: third-factor accounts posit a slightly more complicated structure, but their basic idea is the same one found in Street's grounding account, namely that we can bridge the gap between the normative and non-normative realms by appealing to the grounding relation. ${ }^{51}$ Moreover, once we see this parallel, it is easy enough to formulate a theoreticalreasoning version of a third-factor account in which we imagine a deliberator who knows $(\mathrm{G})$ making use

50 It also faces less serious problems. In particular, its story about how someone apprised of the truth of Humean constructivism is to gain knowledge of her own reasons is rather awkward. In such a case, our deliberator is supposed to run through the following train of thought: "I judge that I have conclusive reason to $\phi$, and my $\phi$-ing does not conflict with anything else I more deeply judge myself to have reason to do. By $\left(\mathrm{G}^{\prime}\right)$ it follows that I have conclusive reason to $\phi$. So I have conclusive reason to $\phi$." Thus our deliberator comes to judge that she has conclusive reason to $\phi$ on the basis of her own judgment that she has conclusive reason to $\phi$, and only the second time around does this judgment constitute knowledge. This is a truly bizarre picture of how knowledge of one's own reasons is possible. (Thus perhaps the best option for Street is to combine a grounding account with respect to one's judgments about one's own reasons with a theoretical-reasoning account with respect to one's judgments about the reasons of others.)

51 Or by appealing to some other non-causal form of dependence, such as constitution or reduction. (See n. 45.) 
of that principle, together with her knowledge that $\mathrm{F}$ obtains, to reason her way to knowledge that $\mathrm{N}$ obtains. All of which suggests the following conclusion: if the antirealist can make use of the theoreticalreasoning account to explain how our normative judgments are able to track the normative truth, then the realist can make use of this account as well. The theoretical-reasoning account is not a distinctively antirealist way of avoiding the Darwinian dilemma. ${ }^{52}$

\section{Hoist by Her Own Petard?}

I have just considered the two different accounts that we find in Street's work of how antirealists in general and Humean constructivists in particular can fend off her evolutionary challenge. I have argued that the first of these - the grounding account - is at best a defense of the epistemic standing of a small subset of our normative judgments, whereas the second - the theoretical-reasoning account - is just as available to the realist as it is available to the antirealist. We have also seen how the grounding account is very similar in spirit to third-factor accounts, and how it is possible to construct a variant of a given third-factor account which makes it into an instance of a theoretical-reasoning account. Given these close parallels between Street's antirealist strategies for defusing the Darwinian dilemma and third-factor ways of defusing that dilemma, it is only natural to revisit Street's "one level up" and "trivially question-begging" objections to third-factor accounts, to see whether they apply to her antirealist strategies as well.

And, in fact, I think it is quite clear that they do. ${ }^{53}$ Recall that according to Street's first objection, third-factor accounts are not a response to the Darwinian dilemma because they rely on grounding claims such as $(G)$, and we can re-run the Darwinian dilemma "one level up" with respect to the third-factor theorist's judgment that $(G)$ is true. A version of this same objection applies to both of Street's antirealist strategies. Both strategies rely on a grounding claim such as $\left(\mathrm{G}^{\prime}\right)$ being judged to be true, either by us as theorists (in the case of the grounding account) or by our imagined deliberator (in the case of the

\footnotetext{
52 A referee offered the following objection to my claim of parity here: maybe the antirealist can avail herself of the theoretical-reasoning strategy whereas the realist cannot because although the realist's dependence claim, $(G)$, is beyond our ken, the antirealist's dependence claim, $\left(\mathrm{G}^{\prime}\right)$, is not beyond our ken. However, this response assumes the very thing which, at this stage in the dialectic, we are aiming to show. The whole point of Street's evolutionary argument is to give us a reason to think that realism faces epistemological difficulties which antirealism does not; we cannot simply assume that conclusion at the outset.
}

53 Russ Shafer-Landau makes a similar point in his 2012, 13-14. 
theoretical-reasoning account). Thus we can re-run the Darwinian dilemma "one level up" with respect to either our or the deliberator's judgment that $\left(\mathrm{G}^{\prime}\right)$ is true. According to Street's second objection, thirdfactor accounts are "trivially question-begging" since they appeal to substantive normative truths such as $(G)$ when trying to explain how our normative judgments track the truth. However, $\left(G^{\prime}\right)$ is just as much a substantive normative truth as $(G)$ is, so Street's two antirealist strategies also involve a question-begging appeal to normative truths, whether on the part of us as theorists (in the grounding account) or on the part of our imagined deliberator (in the theoretical-reasoning account). Conclusion: if third-factor accounts fall prey to Street's "one level up" and "trivially question-begging" objections, then so too do her two antirealist strategies.

Here is another way of reaching that same conclusion. Focus on the grounding account for the moment. (Parallel comments apply to the theoretical-reasoning account.) The grounding account is designed so that it can be appended to Street's adaptive-link account of the evolutionary origins of our normative judgments, as in the left half of Figure 3. But third-factor accounts are also perfectly compatible with the adaptive-link account. The right half of Figure 3 shows one way of embedding the adaptive-link account within a third-factor account. Now stare hard at the dependency structures in the left and right halves of Figures 3. Both dependency structures posit essentially the same story about the causal facts, and both tether that causal story to the normative realm via a grounding link, the only difference being where in the causal story this tether occurs. But why is this a distinction that makes a difference? If it is "trivially question-begging" for the third-factor theorist to tie her tether near the bottom of the causal structure common to the left and right halves of Figure 3, it should also be "trivially question-begging" for the antirealist to tie her tether near the top of that structure. And if we can re-run the Darwinian dilemma on the third-factor theorist's lower-down tether, we should also be able be to re-run that dilemma on the antirealist's higher-up tether. The two dependency structures in Figure 3 are equally question-begging, and they are equally susceptible to additional Darwinian dilemmas "one level up."

Street anticipates that her "one level up" and "trivially question-begging" objections might be thought to apply to the antirealist's position as well as the realist's, and in both cases she replies in the 
grounding + adaptive-link account:

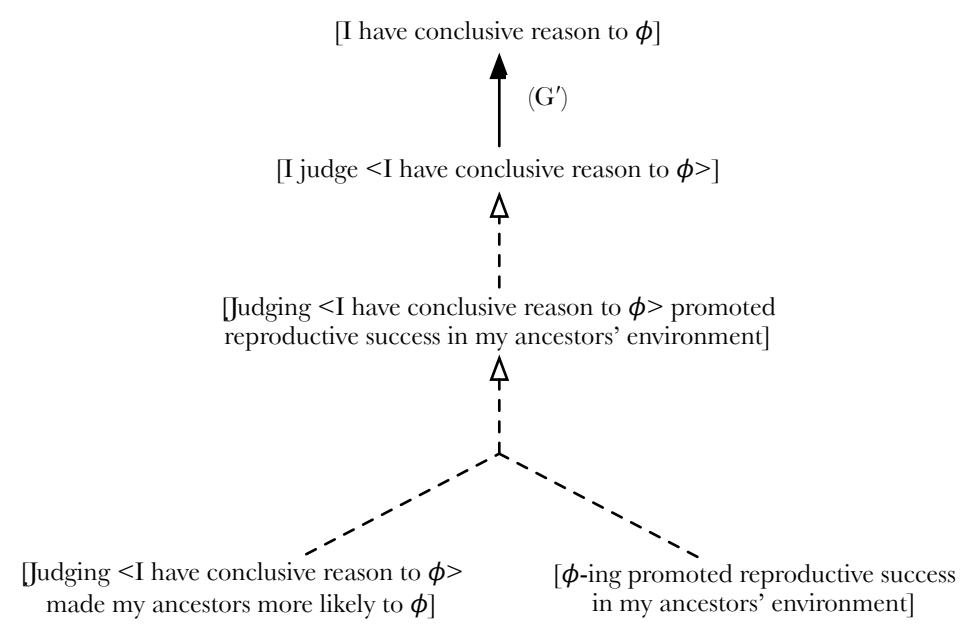

third-factor + adaptive-link account:

[I judge $<$ I have conclusive reason to $\phi>$ ]

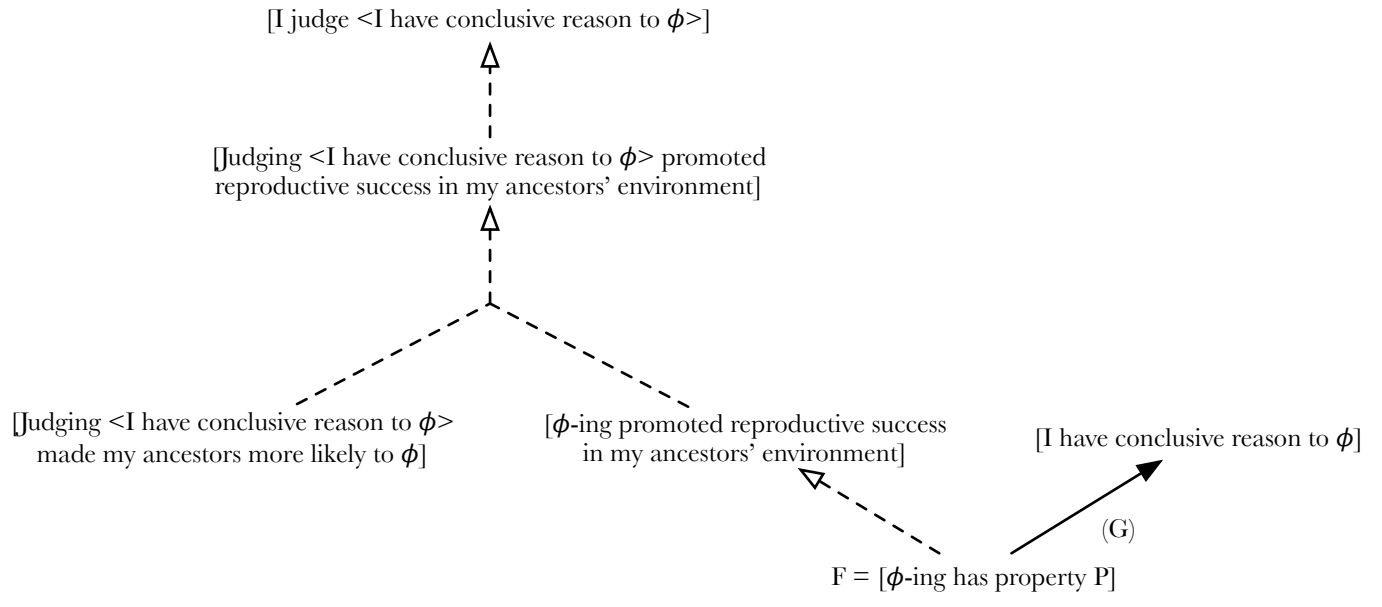

Figure 3. 
same way. She insists that there is no room to run the Darwinian dilemma "one level up" against the antirealist because "in arriving at his or her metaethical view, the antirealist does not need to rely on our substantive [normative] judgments." She continues:

This may be seen by imagining an alien investigator who (1) quite recognizably possesses [normative] concepts; (2) accepts [normative] judgments . . . with entirely different substantive content than our own; and who nevertheless (3) arrives at the same metaethical view as the human antirealist; and (4) does so based on the exact same considerations. Examples of such considerations might include the Darwinian dilemma itself .... (Street 2006, 163n57)

Street's thought here is that if no substantive normative judgments or intuitions are relied upon to reach the truth of antirealism, then we cannot re-run a version of the Darwinian dilemma on the judgments and intuitions which the antirealist uses to support her antirealism, and the antirealist is begging no questions by appealing to the truth of antirealism in the grounding or theoretical-reasoning accounts. Elsewhere, Street makes the same point for the specific case of constructivism (rather than for antirealism in general). She insists that all agents are committed to the truth of constructivism: “. . no matter what one's starting set of normative judgments [is], constructivism follows from within the standpoint constituted by those judgments" (MSb, 37).54 As no normative judgments are used to derive constructivist principles such as $\left(\mathrm{G}^{\prime}\right)$, there are no materials on which to re-run the Darwinian dilemma one level up, and no questions are begged when the antirealist appeals to $\left(G^{\prime}\right)$ during her explanation of how our normative judgments are able to track the attitude-dependent normative truth.

I am deeply suspicious of this reply on Street's part. I mention here three objections. First: her reply doesn't actually address the "trivially question-begging" issue. Suppose that - given Street's understanding of what these expressions come to - it does "follow" from "within" everyone's "practical standpoint" that Humean constructivism is true. This fact is only relevant if we already assume the truth of Humean constructivism, and hence beg the very question at issue. Showing that a theory is by its own

54 Other places where Street asserts that the truth of constructivism follows from any arbitrary set of normative judgments together with the non-normative facts include Street 2009a, 216n7; 2010, 378, 382n16; and MSa, 16-17. Thus Street holds that if $\mathrm{NJ}$ is a fact summarizing a given person's complete set of normative judgments at a given time, NJ grounds the truth of every constructivist claim about the grounds of normative truths. One such claim is $\left(\mathrm{G}^{\prime}\right)$. But another is the claim that NJ grounds the truth of $\left(G^{\prime}\right)$. Therefore we have $\left[\left(G^{\prime}\right) \leftarrow N J,\left[\left[\left(G^{\prime}\right) \leftarrow N\right] \leftarrow N J\right.\right.$, and so on. This is how Street accounts for the infinite hierarchy of groundings "all the way out" to which she is committed by her definition of antirealism. 
lights not question-begging is not the same as showing that a theory is not question-begging. 55

Second objection: despite her claims to the contrary, Street's argument for antirealism in general does, in fact, rely on substantive normative judgments and intuitions. Her Darwinian dilemma against realism relies on substantive normative intuitions of the following sort, among others: intuitions about the epistemic relevance of tracking the truth, intuitions about the good- and bad-making features of explanations (scientific and otherwise), intuitions about the nature of the in-virtue-of relation when it takes normative relata, intuitions about when pain does and does not provide reasons (Street 2006, 149), and intuitions about whether belief attributions qualify as normative judgments (Street 2009a, 224-25). Moreover, Street acknowledges (in her MSb, 31-36) that the Darwinian dilemma on its own is not enough to conclusively support antirealism; one also has to make a case that the force of the Darwinian dilemma in favor of antirealism is not outweighed by the counterintuitiveness of antirealism's apparent consequence that (for example) an ideally coherent Caligula has conclusive reason to torture others for fun. Street devotes an entire article to arguing that this consequence is not as counterintuitive as it might seem (Street 2009b). This, in effect, is to concede that an alien investigator who accepts <An ideally coherent Caligula does not have conclusive reason to torture others for fun> more deeply than any other normative proposition is not committed to the truth of antirealism.

Third objection: Street's argument for Humean constructivism in particular also relies on substantive normative judgments and intuitions. An argument for antirealism is not yet an argument for Humean constructivism. And when we turn to Street's arguments for Humean constructivism, we find a variety of implicit appeals to normative intuitions of a substantive sort. I focus here on two particularly striking examples. The first of these occurs during Street's central defense of Humean constructivism in the case of instrumental normativity. She starts by insisting that the following two claims hold as a matter of conceptual necessity (Street 2008a, 227-29):

55 Suppose I hold a theory on which there is no such thing as the fallacy of begging the question. When you ask me why this theory is true, I say, "My theory is true because it's true. Moreover, I'm not begging the question in asserting this, because there's no fallacy of begging the question." Within the confines of my theory, my reasoning in impeccable. But I nonetheless count as begging the question. 
$\left(\mathrm{C}_{1}\right) \quad$ If $\mathrm{A}$ judges $<\mathrm{I}$ have conclusive reason to $\phi>$, judges $<\mathrm{My} \psi$-ing is a necessary means to my $\phi$-ing $>$, and attends to the matter in full awareness, then A judges $<$ I have a reason to $\psi>.56$

$\left(\mathrm{C}_{2}\right) \quad$ If A judges $<\mathrm{I}$ have conclusive reason to $\phi>$ and it is true that A's $\psi$-ing is a necessary means to A's $\phi$-ing (whether or not $\mathrm{A}$ is aware of this), then by A's own lights $\mathrm{A}$ has a reason to $\psi$.

In the next section (Street 2008a, §8) Street then slides, without argument, from this last claim to the following one:

$\left(\mathrm{C}_{3}\right) \quad$ If A judges $<\mathrm{I}$ have conclusive reason to $\phi>$ and it is true that A's $\psi$-ing is a necessary means to A's $\phi$-ing (whether or not A is aware of this), then A has a reason to $\psi$.

However, this last move requires the backing of substantive intuitions, and it is doubtful that $\left(\mathbf{C}_{3}\right)$ is true as a matter of conceptual necessity (if indeed it is even true). We can see this by considering analogues of these three claims in which A's normative judgments are in the third-person: ${ }^{57}$

$\left(\mathrm{C}_{1}{ }^{*}\right) \quad$ If $\mathrm{A}$ judges $<\mathrm{B}$ has conclusive reason to $\phi>$, judges $<\mathrm{B}$ 's $\psi$-ing is a necessary means to B's $\phi$-ing $>$, and attends to the matter in full awareness, then A judges $<\mathrm{B}$ has a reason to $\psi>$.

$\left(\mathrm{C}_{2}{ }^{*}\right) \quad$ If $\mathrm{A}$ judges $<\mathrm{B}$ has conclusive reason to $\phi>$ and it is true that B's $\psi$-ing is a necessary means to B's $\phi$-ing (whether or not A is aware of this), then by A's lights $\mathrm{B}$ has a reason to $\psi$.

$\left(\mathrm{C}_{3}{ }^{*}\right) \quad$ If $\mathrm{A}$ judges $<\mathrm{B}$ has conclusive reason to $\phi>$ and it is true that B's $\psi$-ing is a necessary means to B's $\phi$-ing (whether or not A is aware of this), then B has a reason to $\psi$.

$\left(\mathrm{C}_{1}{ }^{*}\right)$ and $\left(\mathrm{C}_{2}{ }^{*}\right)$ may well be true as a matter of conceptual necessity, but $\left(\mathrm{C}_{3}{ }^{*}\right)$ is definitely false. Thus there is no easy inference from $<\mathrm{A}$ has, by her own lights, a reason to $\psi>$ to $<\mathrm{A}$ has a reason to $\psi>$, and as a result bridging the gap between $\left(\mathrm{C}_{2}\right)$ and $\left(\mathrm{C}_{3}\right)$ requires substantive judgment.

A second place where Street relies on substantive normative judgments while defending Humean constructivism occurs during her discussion of how Humean constructivists are to handle cases in which an agent's normative judgments conflict with one another. $\left(\mathrm{C}_{3}\right)$ only concerns whether $\mathrm{A}$ has a single pro

56 Actually, Street waffles between two different versions of this principle. Sometimes (Street 2008a, 228; 2012, 43-44) she endorses $\left(\mathrm{C}_{1}\right)$, and other times (Street 2008a, 227; 2010, 374; 2012, 43, 46) she endorses a weaker principle, namely:

$\left(\mathrm{C}_{0}\right) \quad$ If A judges $<\mathrm{I}$ have conclusive reason to $\phi>$, judges $<$ My $\psi$-ing is a necessary means to my $\phi$-ing $>$, and attends to the matter in full awareness, then A doesn't judge $<\mathrm{I}$ don't have a reason to $\psi>$.

$\left(\mathrm{C}_{0}\right)$ is weaker than $\left(\mathrm{C}_{1}\right)$ since $<$ A doesn't judge $<$ not- $p>>$ does not entail $<$ A does judge $<p>>$, even under conditions of full awareness (suspension of judgment is also an option).

57 I learned this trick from Scanlon 1998, 28-29. 
tanto reason to $\psi$; what, though, might we say about the conditions under which instrumental considerations make it the case that $\mathrm{A}$ has conclusive overall reason to $\psi$ ? It is tempting to think that the Humean constructivist should hold

$\left(\mathrm{C}_{4}\right) \quad$ If $\mathrm{A}$ judges $<\mathrm{I}$ have conclusive reason to $\phi>$ and it is true that A's $\psi$-ing is a necessary means to A's $\phi$-ing (whether or not A is aware of this), then A has conclusive reason to $\psi$.

However, $\left(\mathbf{C}_{4}\right)$ quickly leads to paradox. Suppose - to use an example of Street's (2008a, 235) - Beth judges that she has conclusive reason to eat a bowl of chili in front of her, and she also judges that she has conclusive reason to live a long, healthy life. Suppose, moreover, that Beth has a fatal ${ }^{58}$ allergy to peanuts, which unbeknownst to her the bowl of chili in front of her contains. Applying $\left(\mathbf{C}_{4}\right)$ to Beth's first judgment, we get the result that she has conclusive reason to eat the bowl of chili. (A's $\phi$-ing is trivially a necessary means to A's $\phi$-ing.) Applying $\left(\mathbf{C}_{4}\right)$ to Beth's second judgment, we get the result that she has conclusive reason to not eat the bowl of chili. But one can never, at the same time, both have conclusive reason to $\phi$ and have conclusive reason to not- $\phi$. So something has gone wrong. ${ }^{59}$

Street's way out of this problem is to insist that whichever of Beth's two normative judgments is more deeply hers is the one that carries the day. In other words, Street proposes that the Humean constructivist endorse the following instead of $\left(\mathrm{C}_{4}\right)$ :

$\left(\mathrm{C}_{5}\right) \quad$ If A judges $<\mathrm{I}$ have conclusive reason to $\phi>$, A's $\psi$-ing is a necessary means to A's $\phi$-ing, and A's $\psi$-ing does not conflict with anything else she more deeply judges that she has reason to do, then $\mathrm{A}$ has conclusive reason to $\psi$.

However, this move requires the backing of substantive normative judgment: $\left(\mathrm{C}_{5}\right)$ does not follow from $\left(\mathrm{C}_{1}\right),\left(\mathrm{C}_{2}\right)$, and $\left(\mathrm{C}_{3}\right)$ by means of conceptual truths alone. A way of bringing this out is to consider Street's proposal for how to determine which of A's two competing normative judgments is more deeply hers: "this is a function," Street writes, "of how strongly [A] holds the normative judgments in question and how close to the center of [A's] total web of normative judgments they lie" (Street 2008a, 235). But exactly

58 Street says "life-threatening" allergy (2008a, 235), but this is not strong enough to ensure that Beth's not eating the chili is a necessary means to living a long, healthy life. (Another complication: maybe, even though Beth's not eating the chili is necessary for her continuing to live, it is not a means to her continuing to live. But if so, then this is merely a problem for this particular example, and we can easily find another example with the desired structure.)

59 Note that a similar problem does not arise for $\left(\mathrm{C}_{3}\right)$ : there is nothing paradoxical about asserting that Beth both has a pro tanto reason to eat the bowl of chili and has a pro tanto reason to not eat the bowl of chili. 
what function is this? Do we have some way of measuring the strength of a normative judgment, and another way of measuring a judgment's nearness to the center of our agent's total web of normative judgments, and finally a way of combining these two factors into an overall "depth score" that can be compared to the "depth score" for any other normative judgment made by that agent? This suggestion is, of course, absurd. But it brings out the degree to which figuring out the nature of Street's alluded-to function is a highly non-trivial matter. Moreover, it is a matter over which substantive disagreement can occur: if I hold that comparative depth among normative judgments is determined via function $\mathrm{F}_{1}$, and you hold that it is determined via slightly different function $\mathrm{F}_{2}$, it seems a stretch to think that one of us must be conceptually confused. We are in the realm of substantive judgments here, not conceptual truths. ${ }^{60}$

In fact, matters are even worse than this. The sorts of conflict cases that a Humean constructivist must contend with when filling in the details of her theory are not restricted to cases involving an instrumental conflict between a single judgment about what one has conclusive reason to do and another single judgment about what one has conclusive reason to do. The Humean constructivist also owes us a story about what happens in more complex instrumental conflict cases - for example, cases in which A's judgment that she has conclusive reason to $\phi$ conflicts with several of her normative judgments about what she has conclusive reason to do. In such cases do we "add up" the depth score of each of these competing judgments to get a total depth score to compare to that of A's judgment that she has conclusive reason to $\phi$, or is some more complicated aggregation function at work? There are also higher-order conflict cases, such as a case in which A judges that she has conclusive reason to $\phi$, but also judges that she has conclusive

60 In a footnote, Street addresses the worry that she is appealing to substantive assumptions in moving from $\left(\mathbf{C}_{4}\right)$ to $\left(\mathbf{C}_{5}\right)$, but what she says is not unconvincing. She writes:

One might worry that in according priority to those normative judgments which are more strongly held and which lie closer to the core of a person's interlocking web of normative judgments, the account smuggles in a substantive value. My reply is that the priority accorded these normative judgments doesn't reflect a substantive value, but rather reflects the fact that we are asking about agent A's reasons, not someone else's reasons, and agent A is, in an important sense, to be identified with her most strongly and centrally held values. (Street 2008a, 235n45)

There are two problems here. First, the issue of whether $\left(\mathbf{C}_{5}\right)$ relies on substantive normative assumptions is not the same as the issue of whether $\left(\mathrm{C}_{5}\right)$ smuggles in substantive values: not all normative claims are claims about whether something is of value; in particular, some concern how values play off against each other. Second, and more importantly, Street does not avoid appealing to substantive normative assumptions in her reply: the claim <An agent's identity determines what she has reason to do $>$ is a non-trivial claim that requires the backing of substantive normative judgment/intuition to defend. 
reason not to judge that she has conclusive reason to $\phi \cdot{ }^{61}$ Does the higher-order judgment always take precedence in such a case? Or does it matter how strongly held and near to the center of one's web of belief the higher- and lower-order judgments are? Finally, the Humean constructivist must say something about what we might call cross-categorical conflict cases, in which an agent's judgments using one normative category conflict with her judgments using another normative category (together, possibly, with her judgments about how those categories connect). What if A's judgment about her reasons for and against $\phi$-ing are in tension with her judgment that she ought not $\phi$ (together, possibly, with her judgments about the connection between individual reasons and overall oughts)?62 Does whichever of these normative categories is in fact more basic determine which judgment gets priority? Or does it matter which normative category $A$ takes to be more basic? What if the judgments employing the less-basic (or taken-tobe-less-basic) category are more deeply A's than the judgments employing the other category?

I bring up these issues to demonstrate just how complicated filling in the details of Humean constructivism becomes, once we realize the full range of conflicts that can arise amongst a person's normative judgments. In one way, the lack of specifics here is not a problem: sorting out those specifics is a research project waiting to happen, a dissertation begging to be written. However - and this is the central point - that research project does not seem to be one which can be conducted purely through an appeal to conceptual truths. Substantive disagreement over the best way to formulate Humean constructivism is possible, and resolving those disagreements requires making substantive normative judgments and appealing to substantive normative intuitions. Thus it is simply a mistake to say, as Street does, that arguing for Humean constructivism is merely a matter of "descriptive philosophical analysis" in which we figure out "what is constitutive of the . . attitude of normative judgment" without relying on any substantive normative intuitions (Street 2010,374). As a result, Street's way of deflecting her own "one level up" and "trivially question-begging" objections fails.

\footnotetext{
61 If epistemic akrasia is not possible, then this specific example of a higher-order conflict will never arise. But the nonexistence of epistemic akrasia is compatible with other, less extreme varieties of higher-order conflict.

62 Or maybe the mere truth of how individual reasons connect with overall oughts is enough to generate a tension between A's reasons judgments and her ought judgment.
} 


\section{Our Epistemic Predicament}

I have just argued that Street's own metaethical view is just as vulnerable to her evolutionary challenge as realist views are. Where does this leave us? Does this mean that Street's Darwinian dilemma is in fact an argument for normative skepticism?

Not necessarily. Three features of Street's reply to her own "one level up" and "trivially questionbegging" objections are particularly revealing. First, Street's appeal to an alien investigator shows that evolutionary theory is really beside the point in generating her challenge. After all, our alien investigator might not be the outcome of evolutionary forces. Yet our alien investigator is supposed to be able to use a version of the Darwinian dilemma to realize the truth of antirealism. How could this be? Answer: a problem akin to the Darwinian dilemma arises even if the alien investigator was the outcome of non-evolutionary causal forces, or even if the alien investigator popped into existence five minutes ago. ${ }^{63}$ All we need to generate this problem is the fact that our normative judgments have causal origins, regardless of what those origins are. Evolutionary theory makes the causal origins of our normative judgments particularly vivid, but it is not essential for generating the puzzle. ${ }^{64}$

Second, Street's way of trying to fend off her own "one level up" and "trivially question-begging" objections does not actually rely on the antirealist nature of Humean constructivism. The crucial move in Street's reply to those objections is her insistence that the central tenets of Humean constructivism, such as grounding claim $\left(\mathrm{G}^{\prime}\right)$, can be established without appeal to substantive normative judgments and intuitions. The fact that $\left(\mathrm{G}^{\prime}\right)$ grounds a normative fact in facts about our evaluative attitudes plays no role in her response. Swap a different non-normative fact into $\left(\mathrm{G}^{\prime}\right)$ and Street's response would work just as well, provided that the new version of $\left(\mathrm{G}^{\prime}\right)$ can be defended without reliance on substantive normative judgments and intuitions.

But why does Street think that $\left(G^{\prime}\right)$ and the other grounding claims made by the Humean constructivist can be defended without recourse to substantive normative judgments and intuitions? It is

\footnotetext{
63 Or even, I would argue (though I shan't argue for it here), if the alien investigator was created by God.

64 As Street herself admits in the final section of her 2006. Bedke (2009; forthcoming) also stresses that evolutionary influences are just one causal force among many when developing his version of a debunking argument.
} 
because she - mistakenly, I have argued — thinks that $\left(\mathrm{G}^{\prime}\right)$ and the like are conceptual truths. ${ }^{65}$ This leads to my third observation. Really what is doing all of the work in Street's response to her own "one level up" and "trivially question-begging" objections is her contention that the Humean constructivist's central claims about what grounds normative facts are conceptual truths. However, no claims about which nonnormative facts ground normative facts are conceptual truths: Moore's open-question argument blocks all roads here. So what Street is hankering after is impossible.

Thus we should be suspicious of Street's demand that we show, of all the conceptually possible normative truths, that evolution has allowed us to land on the correct one. If the only way of replying to Street's "one level up" and "trivially question-begging" objections is to appeal to normative grounding claims which are conceptual truths, then there is no way to respond to those objections, whether they are leveled against third-factor accounts or against antirealist proposals. Just as Street can ask the third-factor theorist, "Of all the conceptually possible ways in which the normative facts could be partially grounded in the non-normative facts, what are the odds that you've hit on the right one when you judge $(G)$ to be true?" so too we can ask Street, "Of all the conceptually possible ways in which the attitudinal facts might determine the normative facts, what are the odds that you've hit on the right one when you judge $\left(G^{\prime}\right)$ to be true?" Indeed, if conceptual connections are required between successive layers of facts in one's explanation of why a given variety of judgment tracks the truth despite being influenced by evolutionary factors, then Street's "one level up" and "trivially question-begging" objections also apply to explanations of our ability to make judgments about the presence of midsized objects in our immediate environment: "Of all the conceptually possible ways in which the causation relation could work, what are the odds that we've hit on the right one when, in offering Darwinian explanations, we make judgments about the causal properties of predators, progeny, and the like?"66 In short, Street's conceptual demand threatens to make all synthetic knowledge impossible. But it's one thing to voice the old empiricist worry over how synthetic

65 Street often says things like "It is constitutive of normative judgment that $p$," where $<p>$ is some claim about normative judgments, but for her this is just a fancy way of saying, "It is a conceptual truth that $p$." For evidence that she uses these two expressions interchangeably, see Street 2008a, 228; Street 2009a, 226, 228-29, 231-32, 234, 236, 242; and Street 2012, 43, 46, 51,55 .

66 See Clarke-Doane 2012, 323, and forthcoming, 15-16, for a somewhat similar point. 
a priori knowledge is possible, and quite another to call into question synthetic knowledge of any sort. ${ }^{67}$

As a result, I think we should simply ignore Street's insistence that the sort of tracking at issue is tracking with regard to all of the conceptually possible normative truths. The only reasonable demand in the vicinity is one formulated with regard to metaphysically possible truths. This removes one important obstacle to be overcome when answering Street's Darwinian challenge. ${ }^{68}$

What about the remaining obstacles? Let us distinguish between Street's original Darwinian dilemma (as presented in Street 2006) and her amped-up Darwinian dilemma (once considerations about whether an explanation is question-begging are on the table). In response to the original Darwinian dilemma, I think that the following "divide and conquer" strategy is a perfectly adequate response on the part of the realist: 69

- Argue that our tendency to make some normative judgments (such as, perhaps, our tendency to judge that incest is inherently wrong) is the outcome of evolutionary forces pushing us away from the truth.

- Argue that our tendency to make other normative judgments (such as, perhaps, our tendency to judge that our own pain is, other things being equal, to-be-avoided) is the outcome of evolutionary forces pushing us toward the truth, by giving a third-factor account of how this is

67 For similar reasons we should be suspicious of Bedke's appeal to conceptual possibility in his 2009 and forthcoming. Bedke only considers conceptually possible worlds in which all of the natural facts are the same as they are in the actual world but the normative facts are different. However, if we consider conceptually possible worlds in which some of the natural facts are fixed while others vary, Bedke's debunking argument threatens to undermine any justification we might have on the basis for perception for believing synthetic non-normative truths.

68 I have just interpreted Street as holding that the central claims of Humean constructivism are conceptual truths. I do so because I think this is the best way to make sense of why she holds that Humean constructivism can be defended without recourse to substantive normative judgments and intuitions, and the best way to make sense of why she thinks Humean constructivism is better placed than realism to avoid her Darwinian dilemma when that dilemma is formulated in terms of conceptual possibilities. However, more recently (in her MSa, p. 9 of the draft of 20 October 2011), Street tells us that although "there once was a timevery long ago" when she thought that her constructivist account of the grounds of normative reasons was a conceptual truth, she now no longer believes this. (She does not tell us when this change in her thinking occurred.) In the end, this interpretive issue has no bearing on my argument from the past few paragraphs, since I can phrase that argument as a dilemma. Either Humean constructivism is being put forward as a conceptual truth, or it is not. If it is being put forward as a conceptual truth, then Street is right that the theory she puts forward would, if true, be especially well placed to meet a conceptual-possibility-based version of her evolutionary challenge, but this is no help, since that theory is demonstrably false. On the other hand, if Humean constructivism is not being put forward as a conceptual truth, then Street has just as much trouble with the conceptual-possibility-based version of her evolutionary challenge as realists do. Conclusion: it is unreasonable to formulate that challenge in terms of conceptual possibilities.

69 It is also open to the realist to insist that some of our normative judgments are not influenced by evolutionary factors. Derek Parfit (2011, ch. 32-33), Katarzyna de Lazari-Radek and Peter Singer (2012), and Russ Shafer-Landau (2012, 5-8) pursue this strategy. I have been setting that strategy aside in the current chapter, since the primary question I am asking is: if we concede that our normative judgments are heavily shaped by Darwinian forces, what follows? 
possible.

- Argue that our tendency to make yet other normative judgments (such as, perhaps, our tendency to make grounding claims with normative relata) is a byproduct of our having a selected-for general faculty that allows us to make judgments of a given sort, both normative and nonnormative (such as a general faculty for reasoning our way to grounding claims)..$^{70}$

In essence, what I am urging is that the realist survey those of our normative judgments which evolutionary factors push us toward making, and then think hard about the truth of each of those judgments. If the judgment does not strike the realist as being plausible, all things considered, then she should take the first option. If the judgment does strike her as plausible, all things considered, and there is a direct evolutionary story for our tendency to make it, the second option is the way to go. If the judgment strikes the realist as all-things-considered plausible but the evolutionary story for our tendency to make it is an indirect one, then the third option is a possibility. There is no need to adopt a uniform account with regard to all normative judgments.

If this response to the original Darwinian dilemma is successful, then it is also successful against any Darwinian dilemmas that might be offered "one level up." In particular, there is nothing to stop a realist who invokes a third-factor explanation of our ability to reliably make some first-order normative judgment from offering a third-factor account of our ability to make the grounding judgment $(G)$ featured in the original first-order explanation. After all, this in effect is what Street urges when the "one level up" objection is levied against her own explanation of how our first-order normative judgments are able to track the truth. At the first-order level she invokes a Humean constructivist grounding claim. When the Darwinian dilemma is pressed against our ability to judge this grounding claim to be truth, Street appeals

70 At one point (Street 2006, 142-44), Street tries to argue against byproduct hypotheses by re-running her Darwinian dilemma on the relation between the evolutionary forces that shaped the directly selected-for faculty and the attitude-independent normative truths posited by the realist. I lack the space to fully address Street's argument here, but I will offer two comments. First, the new dilemma she presses against byproduct hypotheses is actually quite different in both content and form from her original Darwinian dilemma. (In particular, the relation at issue is not the pushing-toward relation featured in the original Darwinian dilemma. That is why her argument against the "deny a relation" horn of the new dilemma does not appeal to the dire epistemic consequences of embracing that horn, as it did in the original dilemma, and why her argument against the "assert a relation" horn relies on extra steps not present in the original dilemma.) Second, Street's new dilemma nonetheless overlooks many of the same possibilities she neglected when offering her original Darwinian dilemma. (In particular, she continues to assume that the only sort of tracking account available to the realist is a narrow tracking account.) 
to another Humean constructivist grounding claim, namely the claim that the truth of the original Humean constructivist grounding claim is grounded in our evaluative attitudes, since the truth of Humean constructivist follows from within everyone's practical standpoint. When the Darwinian dilemma is pressed against this second grounding claim, Street responds in a similar way, and so on, ad infinitum. But if reiterating the same strategy each level up works for the Humean constructivist, then reiterating the same strategy one level up should work for the realist as well.

And, anyway, we should have been wary of Street's claim that the Darwinian dilemma applies "one level up" with the same force that it applies at the original level. After all, we saw that the adaptivelink account is particularly shaky when it is applied to our tendency to make judgments about in-virtue-ofwhat a given normative claim is true. This problem only becomes worse as we keep going up successive levels: with each stage the force of the first horn of Street's dilemma diminishes, since it becomes less and less clear that we know even the vague outlines of a version of the adaptive-link account that can then be compared in terms of empirical adequacy to a given tracking or third-factor account of the phenomena at that level. Moreover, the force of the second horn also diminishes as we go up levels: it's one thing to be forced to say that we do not know any first-order normative truths, but quite another to say that we lack knowledge of the increasingly complex normative grounding claims invoked in these successive explanations. Indeed, given the current state of play in the field of normative ethics, it seems quite plausible to hold that we lack knowledge of the precise grounding structure both "all the way down" and "all the way out" (if it keeps going out) with respect to even the most obvious of first-order normative truths. ${ }^{71}$

Thus I believe that my "divide and conquer" strategy allows the realist to fend off both Street's original Darwinian dilemma and her "one level up" objection to third-factor accounts. However, that strategy, on its own, does not constitute a reply to Street's "trivially question-begging" worry, and hence does not address her amped-up Darwinian dilemma. After all, a vital part of my "divide and conquer" strategy makes use of third-factor explanations, which invoke normative grounding claims, and we might

\footnotetext{
71 Ignorance of what grounds a truth is compatible with knowledge of that truth. Aristotle knew many truths about water, even though he didn't know that some of those truths hold in virtue of certain truths about hydrogen and oxygen atoms.
} 
worry that in making these claims, we are relying on normative judgments and intuitions that might themselves be "tainted" by evolutionary forces. But now the thing to do is to note that the skeptical worry here is perfectly general: it is just an instance of the general epistemological problem of how we can show that our most fundamental cognitive faculties (perception, introspection, induction, deduction, intuitionwhat have you) are reliable without relying those very faculties when attempting to show this. The Cartesian circle, Chisholm's problem of the criterion, Hume's problem of induction, attempts to justify modus ponens by appealing to modus ponens, the recent literature on bootstrapping and easy knowledgethese are all, I believe, manifestations of the same fundamental epistemological unease. There seems to be something viciously circular about appealing to a given cognitive faculty when attempting to vindicate the epistemic standing of that very faculty. But, with our most basic cognitive faculties, what recourse do we have except to appeal to those faculties during their vindication?

This is a formidable problem - so formidable, in fact, that I think we should countenance the possibility that it has no satisfactory solution. ${ }^{72}$ However, I don't believe that this is a special problem for our normative cognitive faculties. Moreover, it is not a problem that we need to appeal to evolutionary considerations to generate. If we discover tomorrow that all of the evidence for evolutionary theory is an elaborate hoax, we are left with a version of this problem. If we discover (somehow) that we were all created five minutes ago, the problem persists. To generate the problem, we need only start thinking about what makes it the case that our most basic normative cognitive faculties track the truth. Since the truths in question are normative truths, there is no way to approach this problem except through appeal, in part, to our normative cognitive faculties. To think otherwise is to think that it is possible to derive an ought from an is (or, at least, that it is possible to derive a substantive ought from an is plus a conceptual ought).

But what about Street's claim, via Accounts A and B, that the problem here is more pressing for our judgments about normative matters than it is for our judgments about the presence of midsized objects in our immediate environment? Recall the details of Accounts A and B:

72 For my own attempt at a solution, see Berker MSa and MSb. 
Account A: There are six chairs, a laptop, and a table in my immediate environment. But evolutionary forces gave rise to the capacity I used to make this very judgment. This gives me reason to think my capacity about midsized objects in my immediate environment is reliable.

Account B: Midsized objects in our immediate environment are the kinds of things one can run into, be injured by, eat, and be eaten by. Other things being equal, then, creatures with an ability accurately to detect midsized objects in their immediate environment tended to survive and reproduce in greater numbers than creatures who lacked this ability. I am a product of this evolutionary process. This gives me reason to think my capacity to make judgments about midsized objects in my immediate environment is reliable. (Street 2008b, 216-17)

Street claims that Account A is trivially question-begging and gives us no reason to think we're reliable on these matters, whereas Account B is ultimately question-begging but nonetheless gives us good reason to think we're reliable. She also claims that third-factor accounts are of the same form as Account A.

However, neither of these claims is convincing. First, third-factor accounts are actually more like Account B than they are like Account A. ${ }^{73}$ Account B features a variety of specific causal claims which are put together to give us a more complicated causal claim that underwrites the reliability of the very perceptual faculties used to support those original causal claims. Third-factor accounts often feature a variety of specific claims about individual reasons which are put together to give us a more complicated normative claim that underwrites the reliability of the very normative faculties used to support those original claims about reasons.

Second, Account B is, to my mind, just as epistemically problematic as Account A is. Suppose we discover a book of unknown origin that makes various claims about a hitherto undocumented era of the historical past. We begin to wonder whether this book's claims track the truth. Then we find, halfway through the book, an elaborate story about how books of this sort were carefully screened for their accuracy, the unreliable ones being destroyed. (The book contains a story of, as it were, unnatural selection that applies to itself.) Does this story give us any reason to think that our book tracks the truth? I say: no, it does not.

So we are left with a depressingly difficult epistemic problem, one that may well have no satisfying solution. But this is a problem that all metaethical theorists who are not normative skeptics face, regardless of their stance on the mind-dependence of normativity. And it is not a problem unique to the normative realm. The evolutionary origins of our normative faculties do not raise a special problem which only

73 Erik Wielenberg (2010, 459n61) and Ronald Dworkin (2011, 447n9) make similar points. 
antirealists are in a position to solve. Rather, there is a problem here that afflicts all of our faculties, regardless of their origins. ${ }^{74}$

\section{References:}

Bedke, Matthew. 2009. "Intuitive Non-Naturalism Meets Cosmic Coincidence." Pacific Philosophical Quarterly 90: 188-209.

Bedke, Matthew. Forthcoming. "No Coincidence?" To appear in Oxford Studies in Metaethics.

Berker, Selim. MSa. "Graphic Coherence.” In progress.

- MSb. "A Graph-Theoretic Account of Epistemic Structure.” In progress.

-. MSc. "The Unity of Grounding." In progress.

Blackburn, Simon. MS. "Sharon Street on the Independent Normative Truth as Such." Unpublished manuscript. http://www2.phil.cam.ac.uk/ swb24/PAPERS/Meanstreet.htm

Brosnan, Kevin. 2011. "Do the Evolutionary Origins of Our Moral Beliefs Undermine Moral Knowledge?" Biology and Philosophy 26: 51-64.

Chrisman, Matthew. 2010. "Constructivism, Expressivism, and Ethical Knowledge." International fournal of Philosophical Studies 18: 331-53.

Clarke-Doane, Justin. 2012. "Morality and Mathematics: The Evolutionary Challenge." Ethics 122: 31340.

. Forthcoming. "Moral Epistemology: The Mathematics Analogy." To appear in Noûs. Page references are to the online-early version. http://onlinelibrary.wiley.com/doi/10.1111/j.14680068.2012.00875.x/abstract

Copp, David. 2008. "Darwinian Skepticism about Moral Realism.” Philosophical Issues 18: 186-206.

Deem, Michael J. 2012. "Dehorning the Darwinian Dilemma for Realist Theories of Value." Paper presented at the 2012 Harvard-MIT Graduate Philosophy Conference.

De Lazari-Radek, Katarzyna, and Peter Singer. 2012. "The Objectivity of Ethics and the Unity of Practical Reason." Ethics 123: 9-31.

Dreier, Jamie. 2012. "Quasi-Realism and the Problem of Unexplained Coincidence." Analytic Philosophy 53: 269-87.

Dworkin, Ronald. 2011. Fustice for Hedgehogs. Cambridge, MA: Harvard University Press.

Enoch, David. 2010. "The Epistemological Challenge to Metanormative Realism: How Best to Understand It, and How to Cope with It." Philosophical Studies 148: 413-38.

Evans, Matthew, and Nishi Shah. 2012. "Mental Agency and Metaethics." Oxford Studies in Metaethics 7: 80-109.

Gibbard, Allan. 1990. Wise Choices, Apt Feelings. Cambridge, MA: Harvard University Press.

\footnotetext{
74 Versions of this chapter were presented at the 2012 Moral Psychology and Human Agency Workshop at the University of Michigan, as talks at the University of Toronto and the University of Montreal, and in my spring 2013 graduate seminar at Harvard University. I thank the audiences on all of these occasions for their questions and feedback. In particular, conversations with James Bondarchuk, Sarah Buss, Tom Donaldson, Matt Evans, Jeremy David Fix, Thomas Hurka, Jim Joyce, Paul Julian, Guy Kahane, Leonard Katz, Douglas Kremm, Kate Manne, Paul Marcucilli, Jennifer Nagel, Mark T. Nelson, Derek Parfit, Peter Railton, Said Saillant, Andrew Sepielli, Walter Sinnott-Armstrong, Zeynep Soysal, Sarah Stroud, Christine Tappolet, and Sergio Tenenbaum led to changes in the chapter. I also received immensely useful written comments from Fix, Katz, Kremm, and Parfit. Finally, I owe a special debt of gratitude to Justin D'Arms, Daniel Jacobson, and an external referee (since revealed to be Matthew Bedke) for their thoughtful and probing comments on an earlier draft.
} 
Joyce, Richard. 2001. The Myth of Morality. Cambridge: Cambridge University Press.

. 2006. The Evolution of Morality. Cambridge, MA: MIT Press.

—. Forthcoming. "Evolution, Truth-Tracking, and Moral Skepticism." To appear in Problems of Goodness: New Essays on Metaethics, ed. Bastian Reichardt. Bonn: Bernstein Verlag.

Kornblith, Hilary. 1993. "Epistemic Normativity." Synthese 94: 357-76

Manne, Kate. 2014. "Internalism about Reasons: Sad but True?” Philosophical Studies 167: 89-117.

Nozick, Robert. 1981. Philosophical Explanations. Cambridge, MA: Harvard University Press.

Parfit, Derek. 2011. On What Matters. 2 vols. Oxford: Oxford University Press.

Petersen, Steve. 2013. "Utilitarian Epistemology." Synthese 190: 1173-84.

Pust, Joel. 2012. "Intuition.” Stanford Encyclopedia of Philosophy (Winter 2012 Edition), ed. Edward N. Zalta. http://plato.stanford.edu/entries/intuition/

Rosen, Gideon. 2010. "Metaphysical Dependence: Grounding and Reduction." In Modality: Metaphysics, Logic, and Epistemology, ed. Bob Hale and Aviv Hoffmann, 109-35. Oxford: Oxford University Press.

Scanlon, T. M. 1998. What We Owe to Each Other. Cambridge, MA: Harvard University Press.

Shafer-Landau, Russ. 2012. "Evolutionary Debunking, Moral Realism, and Moral Knowledge." Fournal of Ethics and Social Philosophy 7(1): 1-37.

Skarsaune, Knut Olav. 2011. "Darwin and Moral Realism: Survival of the Iffiest." Philosophical Studies 152: 229-43.

Street, Sharon. 2006. “A Darwinian Dilemma for Realist Theories of Value.” Philosophical Studies 127: 109-66.

—. 2008a. "Constructivism about Reasons." Oxford Studies in Metaethics 3: 207-45.

. 2008b. "Reply to Copp: Naturalism, Normativity, and the Varieties of Realism Worth Worrying About." Philosophical Issues 18: 207-28.

. 2009a. "Evolution and the Normativity of Epistemic Reasons." Canadian Fournal of Philosophy, Supplement 35: 213-48.

2009b. "In Defense of Future Tuesday Indifference: Ideally Coherent Eccentrics and the Contingency of What Matters." Philosophical Issues 19: 273-98.

- 2010. "What Is Constructivism in Ethics and Metaethics?" Philosophy Compass 5(5): 363-84.

. 2011. "Mind-Independence without the Mystery: Why Quasi-Realists Can't Have It Both Ways." Oxford Studies in Metaethics 6: 1-32.

. 2012. "Coming to Terms with Contingency: Humean Constructivism about Practical Reason."

In Constructivism in Practical Philosophy, ed. James Lenman and Yonatan Shemmer, 40-59. Oxford: Oxford University Press.

. MSa. "How to Be a Relativist about Normativity." Unpublished manuscript. https://files.nyu .edu/ss 194/public/sharonstreet/Writing_files/Paper $\% 2013 \% 20$ for $\% 20$ website $\% 20$ $\% 20 \mathrm{How} \% 20$ to $\% 20 \mathrm{Be} \% 20 \mathrm{a} \% 20$ Relativist $\% 20$ About $\% 20$ Normativity.pdf

—. MSb. "Objectivity and Truth: You'd Better Rethink It." Unpublished manuscript. https://files .nyu.edu/ss 194/public/sharonstreet/Writing_files/Paper\%2012\%20for\%20website\%20$\% 20$ Objectivity $\% 20$ and $\% 20$ Truth $\% 20-\% 20$ You $\% 27 \mathrm{~d} \% 20$ Better $\% 20$ Rethink $\% 20$ It.pdf

Wielenberg, Erik. 2010. "On the Evolutionary Debunking of Morality." Ethics 120: 441-64. 